Neth. J. Pl. Path. 97 (1991)25-54

\title{
Simulation of damage in winter wheat caused by the grain aphid Sitobion avenae. 2. Construction and evaluation of a simulation model
}

\author{
W.A.H. ROSSING
}

Department of Theoretical Production Ecology, Wageningen Agricultural University, P.O. Box 430, $6700 \mathrm{AK}$ Wageningen, the Netherlands

Accepted 30 October 1991

\begin{abstract}
To evaluate the relative importance of various components of damage caused by grain aphid (Sitobion avenae F.) populations in winter wheat, a simulation model of crop growth and development is combined with a model of aphid injury. The model applies to the time interval from flowering to ripeness which constitutes the main period of grain aphid immigration and development in winter wheat in the Netherlands. The crop model describes crop growth and development as a function of the prevailing weather and the available amount of soil nitrogen and consists of sink-source relations and distribution functions for carbohydrates and nitrogen. Injury by $S$. avenae affects crop growth both directly and indirectly. Direct effects on growth are due to aphid feeding. Indirect effects are caused by the aphid excretion product honeydew which affects leaf net carbon dioxide assimilation. Alternative hypotheses on the nature of the direct effects are formulated. Inputs to the model are average daily temperature, daily global radiation, the amount of nitrogen in the soil and the density of the aphid population. The major output is grain weight.

The accuracy of the model is assessed by visual and statistical comparison to field data. The accuracy of both crop and damage model is satisfactory except for the final part of the growing season. Then, insufficient information on processes involved in leaf death and the termination of phloem transport to the grains results in overestimation of the rate of grain filling.

The consequences of the lack of detailed information on the relation between environmental factors and the effect of honeydew on leaf carbon dioxide assimilation are assessed in a sensitivity analysis.
\end{abstract}

Additional keywords: photosynthesis, carbon dioxide assimilation, sink-source relations, honeydew, validation, sensitivity analysis.

\section{Introduction}

Economic losses in winter wheat due to infestation by the grain aphid (Sitobion avenae F.) have been reported from most western European countries (Kolbe, 1969; George, 1974; Latteur, 1976; Dedryver, 1978; Vereijken, 1979; Reitzel and Jakobsen, 1980). Regression models for damage forecasting have been developed based on growth analysis of wheat crops infested with aphid populations of various sizes and during various periods of time (Wratten, 1978; Vereijken, 1979; Wetzel et al., 1980; Lee et al.,1981; Rabbinge and Mantel, 1981; Watt et al., 1984; Entwistle and Dixon, 1987). 
The accuracy of a number of these regression models is discussed by Entwistle and Dixon (1987). Rabbinge and Mantel (1981) and Rabbinge et al. (1983) hypothesized that the yield level of the uninfested crop should be considered in the analysis of aphid damage, as the effect of the aphids on crop physiologic processes is not constant nor linearly related to yield. Adaptation of the forecasting models to various attainable yield levels would require numerous additional experiments. Moreover, as the causes of damage are not taken into account, the range of situations in which a regression model can be used is restricted to the range used in its construction.

An alternative approach is to predict crop yield from knowledge of plant physiologic and crop ecologic processes and the way they are affected by S. avenae. The outlines of this eco-physiologic approach to crop-pest interaction have been described by Rabbinge and Rijsdijk (1981), Boote et al. (1983), Rabbinge (1985) and Rabbinge et al. (1989). Taking this approach, an aphid - winter wheat model is described and evaluated. The model simulates crop growth and development from anthesis to ripeness as function of the prevailing weather, the available amount of soil nitrogen and the aphid infestation present. Water is assumed not to be limiting. The model is used to assess the contribution of various injury components of $S$. avenae to damage and to evaluate the consequences of the lack of detailed information on some processes in the aphid - winter wheat system for predicted yield.

\section{Materials and methods}

\section{Model for crop growth}

An adapted version of the NWHEAT model (Groot, 1987) is used to simulate postanthesis growth and development of winter wheat in the absence of aphids as a function of prevailing temperature and radiation and the available amount of nitrogen in the soil.

The core of the model consists of relations which describe the supply and demand of carbohydrates and nitrogen, respectively. Carbohydrates produced by carbon dioxide assimilation are used for maintenance respiration and growth of the grains, the sinks in order of priority. Surplus of carbohydrates is stored temporarily in the stems before relocation to the grains. The actual rate of carbohydrate transport from the sources to the sinks equals the demand ('sink-limited growth') or the supply ('source-limited growth'), whichever is the smallest. Nitrogen is taken up from the soil into the vegetative plant parts: leaves, stems and ear structures other than grains. In these vegetative plant parts nitrogen is incorporated in structural material ('residual nitrogen') and in proteins ('translocatable nitrogen'). The latter fraction is the source of nitrogen redistribution to the grains, the only sink. The actual rate of nitrogen transport from the source to the grains is calculated in analogy with the procedure for carbohydrates. In the model the carbohydrate and nitrogen balances interact as the rate of carbon dioxide assimilation at high light intensities is positively correlated with the weight fraction of translocatable nitrogen in the vegetative organs. Also, when the translocatable nitrogen fraction of a vegetative organ decreases below a critical level, the organ dies at a constant relative rate. The rate of crop development is described as a linear function of temperature. The threshold temperature for crop development is $9{ }^{\circ} \mathrm{C}$. A detailed description of the model is given by Groot (1987). 
Table 1. Inputs for the crop model.

\begin{tabular}{ll}
\hline Site variables & Latitude \\
Meteorologic variables & Maximum daily temperature* \\
& Minimum daily temperature* \\
& Total global radiation* \\
Soil variables & Amount of total available nitrogen in the soil from anthesis to harvest* \\
Crop variables & Dry weight of green leaves*, stems* and ears* at anthesis \\
& Nitrogen concentration of green leaves*, stems*and ears* at anthesis \\
& Amount of soluble carbohydrates in the stems at anthesis* \\
& Tiller density at anthesis* \\
& Grain density* \\
& Leaf area index of leaves* and ears* at anthesis \\
& Date of anthesis* \\
& Date of harvest
\end{tabular}

* Variables used in the input error analysis

The model is modified in three areas. Firstly, to accomodate calculation of light interception by the ears the distribution of light within the ear layer is calculated according to the procedure described by Goudriaan (1988), assuming the angle distribution of the ears to be uniform between 60 and 120 degrees relative to the horizontal. Secondly, the relative death rate of leaves is modified according to Van Keulen and Seligman (1987). The relative death rate depends on the actual content of translocatable nitrogen relative to a maximum content deduced from experiments with high nitrogen fertilizer input. In the model, the relative rate of leaf death increases linearly from zero, at relative nitrogen contents of 0.9 and higher, to 0.2 day $^{-1}$ at relative nitrogen contents of 0.4 and lower. Moreover, leaves are assumed to die at a relative rate of 0.03 day $^{-1}$ due to mutual shading which occurs if the leaf area index exceeds the value of $4 \mathrm{~m}^{2} \mathrm{~m}^{-2}$. Finally, shortage of carbohydrates, occurring when the maintenance respiration of the crop exceeds gross carbon dioxide assimilation, causes leaf death.

The final adaptation concerns the onset of grain filling which is estimated to occur at 0.11 of the period of physiological time from anthesis to dead ripeness, approximately coinciding with DC 71 (Decimal Code for crop development, Zadoks et al., 1974) according to results of an extensive literature survey by Van Keulen and Seligman (1987).

Inputs to the model are shown in Table 1. Grain yield is the major output. The model is written in CSMP, Continuous System Modelling Program (IBM, 1975). Time interval of rectilinear integration is one day.

\section{Model for damage}

Sitobion avenae affects growth of the winter wheat crop both directly and indirectly (Rabbinge and Mantel,1981; Rabbinge et al., 1981; Wellings et al., 1989). The direct effects on growth result from removal of carbohydrates and nitrogen by phloem sap feeding of aphids. Indirect effects come about through honeydew deposition onto photosynthetically active plant surfaces.

Neth. J. Pl. Path. 97 (1991) 


\section{Direct effects}

Concept. In the model, uptake of phloem sap by feeding aphids is conceptually identical to the uptake of phloem sap by growing grains. Both aphids and grains are sinks characterized by a demand for carbohydrates and nitrogen. Information in the literature strongly suggests that aphids primarily exert a demand for nitrogen while carbohydrates are ingested concomitantly. Mittler (1958) assumed on the basis of his results with Tuberolachnus salignus (Gmelin) that an increase in $\mathrm{N}$-content in the phloem sap enhances the growth rate of the aphid and diminishes the excretion rate. Hertel and Kunkel (1976) established a negative correlation between the concentration of amino acids in the artificial diet and the amount of carbohydrates excreted by Myzus persicae (Sulz.). Vereijken (1979) found a higher honeydew production of S. avenae on plants with a low nitrogen status than on plants well supplied with nitrogen. Jensen (1969) reported that barley plants infected with barley yellow dwarf virus had increased levels of soluble nitrogen while Ajayi and Dewar (1982) reported Metopolophium dirhodum (Wlk.) feeding on BYDV infected plants to produce significantly less honeydew per day than on control plants. These data indicate that aphids adjust their feeding rate according to the availability of nitrogen at the feeding site, the sieve tubes of the phloem (Dixon, 1975). Therefore, in the model the nitrogen demand of the aphids determines their rate of ingestion of phloem sap.

The partitioning of nitrogen in the phloem sap between aphids and grains can be described in different ways, the exact interaction between these sinks not being known. Here, four hypotheses concerning the partitioning are formulated and their consequences for damage are evaluated. Aphids may be the first to utilize the flow of nitrogen due to their feeding position in the rachis at the base of the grains. After the demand of the aphids is met, the remainder of the phloem sap nitrogen is utilized by the grains, whose demand may thus not be fully met. Alternatively, aphids may be assumed to share the nitrogen flow with the grains in proportion to their sink strength (Fig. 1). Aphid feeding may be compensated for by an increase in the flow of nitrogen from the source. Assuming full compensation, the net flow rate of nitrogen is determined by the sum of demands of aphids and grains. Alternatively, no compensation may occur. Summarizing, the four hypotheses concerning partitioning of phloem sap nitrogen are (Fig. 1):

$(I)$ : compensation for aphid feeding by increased total demand, which is equal to the sum of demands of grains and aphids; the flow of nitrogen is distributed in proportion to the respective demands.

(II): compensation for aphid feeding by increased total demand, which is equal to the sum of demands of grains and aphids; the flow of nitrogen is first utilized by the aphids.

(III): no compensation for aphid feeding: total demand is equal to the demand of grains; the flow of nitrogen is distributed in proportion to the respective demands of grains and aphids.

(IV): no compensation for aphid feeding: total demand is equal to the demand of grains; the flow of nitrogen is first utilized by the aphids.

The rate of carbohydrate ingestion is assumed to be equal to the product of the weight ratio of carbohydrates and nitrogen in the phloem sap and the rate of nitrogen uptake.

Quantification. Coster (1983) in Rabbinge and Coster (1984) measured daily honey- 


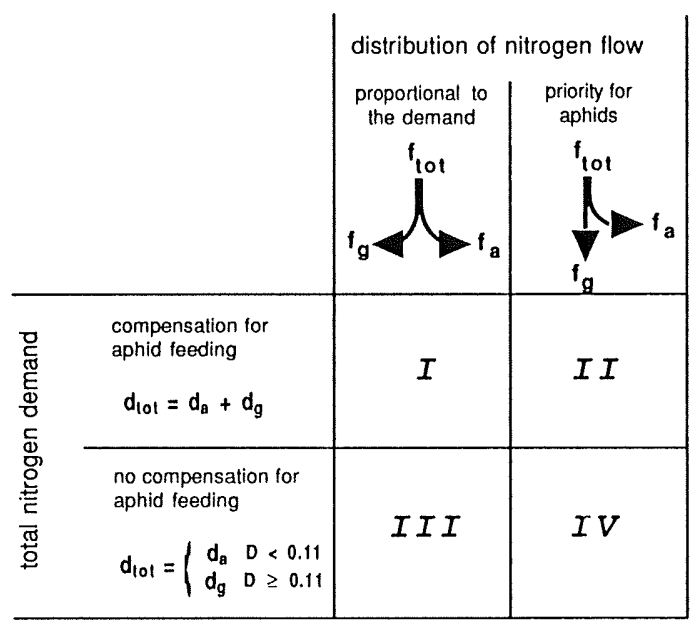

Fig. 1. Illustration of hypotheses I to IV which describe the effect of aphids on the size of the sink for nitrogen in the plant ('total nitrogen demand') and the partitioning of phloem sap nitrogen between aphids and grains ('distribution of nitrogen flow'). The variables $f, d$ and $D$ indicate the actual flow to a sink, the demand of a sink and the development stage of the crop, respectively. The suffixes tot, $g$ and a represent the total sink, the grain sink and the aphid sink, respectively ( $c f$. Appendix I).

dew production rates of $S$. avenae on flag leaves and ears of spring wheat plants at various crop development stages. The plants were well supplied with water and nitrogen. The rate of phloem sap uptake was calculated by applying an energy budget approach (e.g. Llewellyn, 1988). The results are shown in Table 2. To calculate the nitrogen demand of the aphids from these data, the feeding rate must be related to the nitrogen content of the phloem sap at the time of uptake. The total nitrogen

Table 2. Rate of phloem sap feeding ( $\mathrm{mg}$ (phloem sap dry weight) $\mathrm{mg}^{-1}$ (aphid fresh weight) $\mathrm{day}^{-1}$ ) and rate of honeydew production ( $\mathrm{mg}$ (honeydew dry weight) $\mathrm{mg}^{-1}$ (aphid fresh weight) day $^{-1}$ ) of $S$. avenae on spring wheat var. Bastion. Each figure is the average of 10 replicates. The weight fraction dry matter in phloem sap is 0.2. Data of Coster (1983) and Rabbinge \& Coster (1984).

\begin{tabular}{lllll}
\hline $\begin{array}{l}\text { Feeding } \\
\text { position } \\
\text { of aphids }\end{array}$ & $\begin{array}{l}\text { Crop } \\
\text { stage }\end{array}$ & $\begin{array}{l}\text { Feeding } \\
\text { rate }\end{array}$ & $\begin{array}{l}\text { Honeydew } \\
\text { production }\end{array}$ & $\begin{array}{l}\text { N-content } \\
\text { of flagleaves }(\mathrm{f}) \\
\text { or ears (e) }\left(\mathrm{gg}^{-1}\right)\end{array}$ \\
flag leaf & 45 & 0.45 & 0.15 & - \\
flag leaf & 45 & 0.51 & 0.19 & $45.7(\mathrm{f})$ \\
ear & 65 & 0.45 & 0.18 & - \\
ear & 69 & 0.31 & 0.09 & $35.6(\mathrm{e})$ \\
ear & 71 & 0.33 & 0.13 & $22.6(\mathrm{e})$ \\
ear & 73 & 0.17 & 0.06 & $24.7(\mathrm{e})$ \\
ear & 75 & 0.24 & 0.08 & $23.5(\mathrm{e})$ \\
\hline
\end{tabular}

Neth. J. Pl. Path. 97 (1991) 
content of the flag leaves and ears, which was determined in the experiments of Coster, cannot be used for this purpose since in green tissue nitrogen is mainly present in proteins while in phloem sap nitrogen in predominantly found in amino-acids and amides. Here, the nitrogen content of the phloem sap in the experiments is estimated to be $2 \%$ of phloem sap dry weight, a figure representing the average nitrogen content of grains early during grain filling. Furthermore, the assumption is made that the nitrogen demand of aphids feeding on ears was fully satisfied at the highest feeding rate measured by Coster (1983). Lower feeding rates are attributed to mechanical and physiological changes associated with ripening of the crop. Thus a value of $8.9 \times$ $10^{-9} \mathrm{~kg}(\mathrm{~N}) \mathrm{mg}^{-1}$ (aphid, fresh weight) day ${ }^{-1}$ is obtained for the potential feeding rate $\left(p_{\mathrm{a}}\right)$. The nitrogen demand by the aphid population is described by

$$
d_{\mathrm{N}, \mathrm{a}}=p_{\mathrm{a}} \cdot w_{\mathrm{a}} \cdot n_{\mathrm{a}} \cdot n_{\mathrm{t}}
$$

where $d_{\mathrm{N}, \text { a }}=$ potential rate of nitrogen accumulation in the aphids $\left(\mathrm{kg}(\mathrm{N}) \mathrm{ha}^{-1}\right.$ day $\left.^{-1}\right), p_{\mathrm{a}}=$ potential feeding rate $\left(\mathrm{kg}(\mathrm{N}) \mathrm{mg}^{-1} \mathrm{day}^{-1}\right), w_{\mathrm{a}}=$ average aphid fresh weight (mg), $n_{\mathrm{a}}=$ aphid density (tiller $\left.{ }^{-1}\right), n_{1}=$ tiller density (ha ${ }^{-1}$ ).

Average aphid fresh weight depends on the age composition of the population. When no detailed population census has been made, average aphid weight is calculated from total aphid density using crop development stage dependent conversion factors calculated by Mantel et al. (1982). Concomitant with nitrogen, carbohydrates are taken up by the aphids. Analogous to the grains, a potential rate of carbohydrate accumulation is defined for the aphids which is a function of the potential rate of nitrogen uptake:

$$
d_{\mathrm{C}, \mathrm{a}}=c_{\mathrm{r}} \cdot d_{\mathrm{N}, \mathrm{a}}
$$

where $d_{\mathrm{C}, \mathrm{a}}=$ potential rate of carbohydrate accumulation in the aphids $\left(\mathrm{kg}\left(\mathrm{CH}_{2} \mathrm{O}\right)\right.$ $\mathrm{ha}^{-1}$ day $\left.^{-1}\right), c_{\mathrm{r}}=$ the ratio of the amounts of carbohydrates and nitrogen in the phloem sap $\left(\mathrm{kg}\left(\mathrm{CH}_{2} \mathrm{O}\right) \mathrm{kg}^{-1}(\mathrm{~N})\right)$. The dynamic function $c_{\mathrm{r}}$ is calculated from the actual rates of carbohydrate and nitrogen flow to the sinks one integration interval earlier.

Total demands for nitrogen and carbohydrates are formulated for each of the hypotheses. After calculating the actual flows of nitrogen and carbohydrates according to the sink-source concept, the flows are distributed over the sinks, depending on the hypothesis on the nature of the aphid-grain competition for phloem sap. The actual relations are given in Appendix I.

\section{Indirect effects}

Concept. Honeydew produced by $S$. avenae feeding on ears is intercepted by ears, stems, leaves and ground. The interception of honeydew by the various plant parts is modelled in analogy with interception of light. Given the effect of honeydew on leaf carbon dioxide assimilation at every point in the crop profile, daily crop carbon dioxide assimilation can be calculated.

Experimental results of Rossing and Van de Wiel (1990) suggest that the effect of honeydew on carbon dioxide assimilation of winter wheat leaves depends on environmental conditions: temperature, relative humidity, dew and rain. Part of the effect of 
honeydew is attributable to saprophytic micro-organisms in the phyllosphere. These saprophytes may increase the rate of dark respiration and decrease the initial light use efficiency at suitable environmental conditions. At present, information on the quantitative effect of environmental factors on the population dynamics of saprophytes and their interaction with leaf carbon dioxide assimilation is lacking.

In experiments under dry conditions which precluded growth of saprophytes, an effect of honeydew per se on leaf carbon dioxide assimilation was found (Rossing and Van de Wiel, 1990). This effect of honeydew consists of an increased rate of dark respiration and a reduction of the rate of carbon dioxide assimilation at light saturation, fifteen days after application of the honeydew. Here, these results are used to describe the effects of honeydew on carbon dioxide assimilation. The potential contribution of the saprophytic leaf mycoflora to damage is evaluated in the sensitivity analysis.

Quantification. According to data of Coster (1983), fourty $\%$ of the ingested phloem sap is excreted as honeydew:

$$
h=0.40 \cdot f_{\text {c, a }}
$$

with $h=$ rate of honeydew excretion $\left(\mathrm{kg} \mathrm{ha}^{-1} \mathrm{day}^{-1}\right), f_{\mathrm{c}, \mathrm{a}}=$ actual flow of carbohydrates to the aphids $\left(\mathrm{kg} \mathrm{ha}^{-1} \mathrm{day}^{-1}\right)$.

According to Vereijken (1979), thirty percent of the daily honeydew production lands on the ears, the remainder being intercepted by leaves, stems and ground. Honeydew intercepted by the ears is distributed uniformly over the ear surface. Applying the concepts developed for ligitt (Spitters, 1986) the rate of honeydew interception at depth $L$ in the leaf and stem layer of the canopy, with $L=0$ at the top of the canopy, is:

$$
h_{\mathrm{Is}}(L)=\left(1-e_{\mathrm{f}}\right) \cdot h \cdot k_{\mathrm{h}} \cdot \exp \left(-k_{\mathrm{h}} \cdot L\right)
$$

with $h_{\mathrm{Is}}(L)=$ rate of honeydew interception at depth $L$ in the leaf and stem layer $(\mathrm{kg}$ $\mathrm{ha}^{-1}$ day $\left.^{-1}\right), L=$ cumulative leaf area index calculated from the top of the leaf and stem layer $\left(\mathrm{ha} \mathrm{ha}^{-1}\right), e_{\mathrm{f}}=$ fraction of the total honeydew production intercepted by ears $(-), k_{\mathrm{h}}=$ extinction coefficient for honeydew (-). The value of $k_{\mathrm{h}}$ was estimated to be 0.8 , equal to the value of the extinction coefficient for diffuse light intercepted by black leaves (i.e. no transmission or reflection) with a spherical leaf angle distribution (Goudriaan, 1988).

The increase in the rate of dark respiration and the decrease in the rate of carbon dioxide assimilation at light saturation are functions of the amount of honeydew deposited and the period of time elapsed since deposition. The size of the effects is approximately proportional to the amount of honeydew applied (Rossing and Van de Wiel, 1990) (Fig. 2). In the model, no response is allowed above the maximum values measured. The effects are assumed to come about at a constant rate from the time of deposition. The increase in dark respiration is assumed to be caused by an increase in maintenance respiration only. The total effect of honeydew depositions ('droplets') of various sizes and ages is calculated by adding the effects of the individual droplets. Overlapping of droplets is assumed to be absent. The resultant fraction reduction of the rate of carbon dioxide assimilation at light saturation and the fraction increase in 

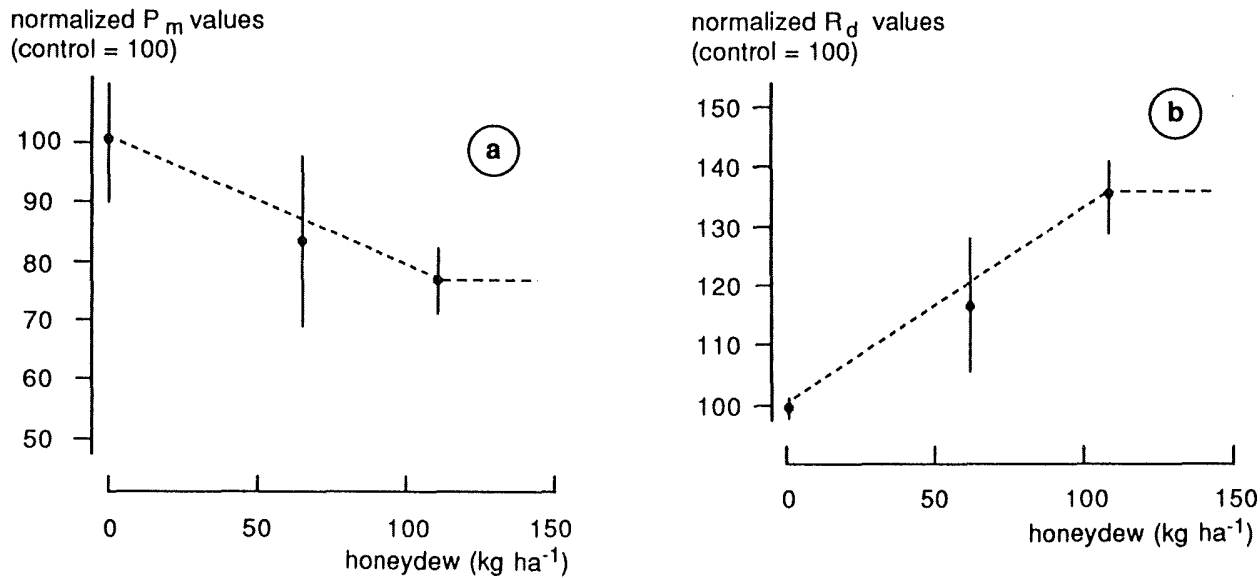

Fig. 2. The effect of honeydew on carbon dioxide assimilation of flag leaves of winter wheat relative to the control, 15 days after deposition: (a) the effect on the rate of carbon dioxide assimilation at light saturation $\left(P_{\mathrm{m}}\right)$ and (b) the effect on the rate of dark respiration $\left(R_{\mathrm{d}}\right)$, based on the data of Rossing and Van de Wiel (1990). Error bars represent the standard error of the mean. The dotted lines are used in the simulation model.

the rate of respiration are inputs for the carbon dioxide assimilation algorithm of the crop model.

\section{Results and discussion: Model evaluation}

\section{Introduction}

The process of model evaluation may be divided into verification and validation. Verification comprises the process of ensuring that a model behaves as the experimenter wants it to and validation the testing for agreement in behavior between model and real system (Teng et al., 1980). Verification also involves parameterization, the process in which parameters are adjusted to optimally represent the real system. Here, the data sets PAGV1 and EEST84 were used to adjust the rate of leaf carbon dioxide assimilation at light saturation and the onset of leaf death due to nitrogen shortage.

The most common method for model validation is probably visual inspection of similarity between model output and real system behavior. Though some authors argued that validation should largely be a subjective procedure (Anderson, 1974), other authors have stressed the importance of supplementing visual inspection with statistical procedures (Teng et al., 1980; Ten Berge, 1990).

In this paper, two categories of error in model output are distinguished, (a) model parameterization and structure and (b) model input. Model parameterization and structure are validated by visual comparison of model output with system behavior, and by sensitivity analysis. Criteria used for visual validation include similarity of the simulated and observed rates of change of selected variables, the coincidence in time of abrupt changes in simulated and observed variables and the size of the discrepancy 
between simulated and observed results relative to the variation in the observations. Three variables are selected for visual validation: leaf weight, leaf nitrogen amount and grain yield. Leaf weight and leaf nitrogen amount determine to a large extent the size of the sources of carbohydrates and nitrogen, respectively, while grain yield is the variable of major interest. In the sensitivity analysis the effect of changes in model parameters ('fine sensitivity analysis') and in model structure ('coarse sensitivity analysis') on the value of output variables is examined (Carter and Rabbinge, 1980). The relative sensitivity $(\Delta z / z) /(\Delta y / y)$ is used as a measure of model sensitivity to changes in a parameter, where $z$ is the value of the relevant model output variable, $y$ the value of the parameter and $\Delta z$ the change in $z$ caused by a change $\Delta y$ in $y$. The size of the perturbation $\Delta y$ is taken to be of the order of the variation of $y$ reported in the literature.

Up to this point, empirically determined model inputs, initial values of state variables and the time course of exogenous variables, are considered exact estimates. Due to spatial heterogeneity in the field they are in fact mean values of probabilistic variables. Hence, model output is probabilistic and, during validation, is to be compared with probabilistic observed system behavior. Ten Berge (1990) proposed a statistic to evaluate the variance of model output in relation to the variance of measured variables as a function of time, defined as

$$
q(\mathrm{t}) \equiv \frac{\left[z_{0}(t)-z_{\mathrm{s}}(t)\right]}{\sqrt{\operatorname{var}\left[z_{0}(t)\right]+\operatorname{var}\left[z_{\mathrm{s}}(t)\right]}}
$$

where $z_{\mathrm{o}}(t)$ and $z_{\mathrm{s}}(t)$ represent the observed and the simulated quantities at time $t$, respectively, and $\operatorname{var}\left[z_{0}(t)\right]$ and $\operatorname{var}\left[z_{\mathrm{s}}(t)\right]$ the respective error variances. The error variance of $z_{\mathrm{s}}(t)$ is approximated as a function of the error variances of the input variables $x_{\mathrm{i}}(i=1, \ldots, n)$ by:

$$
\operatorname{var}\left[z_{\mathrm{s}}(t)\right] \approx \sum_{i=1}^{n}\left[\frac{\Delta z_{\mathrm{s}}}{\Delta x_{\mathrm{i}}}\right]^{2} \operatorname{var}\left(x_{\mathrm{i}}\right)
$$

where $\Delta z_{\mathrm{s}} / \Delta x_{\mathrm{i}}$ is the sensitivity of $z_{\mathrm{s}}(t)$ to changes in $x_{\mathrm{i}}$ and $\operatorname{var}\left(x_{\mathrm{i}}\right)$ the error variance of $x_{\mathrm{i}}$ calculated as the sample variance divided by the number of units in the sample. The equation has been derived for uncorrelated inputs $x_{\mathrm{i}}$ by Hahn and Shapiro (1967). In the present context the variable $z_{\mathrm{s}}$ represents grain yield and $x_{\mathrm{i}}$ the various model inputs. The sensitivity $\Delta z_{s} / \Delta x_{i}$ is assessed by running the model with the average plus and minus one standard error of the input, respectively, and calculating the average $\Delta z_{\mathrm{s}} / \Delta x_{\mathrm{i}}$ to account for non-symmetrical response. Interactions in $\Delta z_{\mathrm{s}} / \Delta x_{\mathrm{i}}$ of the various inputs are ignored and the distribution of errors in $x_{\mathrm{i}}$ is assumed to be normal. Under the null hypothesis of correctness of the model, the expectation of $q(t)$ is 0 . In analogy with the related Student $t-s t a t i s t i c$, predictions are considered reasonable if the value of $q(t)$ ranges between -2 and +2 . 


\section{The crop model}

\section{Data for validation}

Six data sets from three locations and two years are available for validation of the crop model (Table 3). Four of these, EEST83, PAGV1, PAGV2, and PAGV3, originate from experiments designed to determine the optimum rate of fertilizer supply (Groot, 1987). Weeds, diseases and aphids were treated chemically on occurrence. The data sets are chosen to represent a range of grain yields which were arrived at under conditions of nitrogen limitation only. Calculations using a crop model with a water balance showed that effects of water limitation after flowering were negligible in these experiments (personal communication J.J.R. Groot).

Two other data sets, BOUWING84 and EEST84, stem from the aphid-free control treatment of experiments designed to evaluate the damage model (Rossing and Van de Wiel, 1990). A slight aphid infestation in the control treatment could not be avoided due to immigration from neighbouring plots. In view of the rainfall frequency (Rossing and Van de Wiel, 1990) and the soil type (Table 3), water limitation is assumed absent.

All data pertain to the cultivar Arminda. Weather data are collected at the weather station closest to the respective experimental site. All model validation runs are carried out with measured temperature, radiation and soil nitrogen data. The crop development rate is introduced as it was observed to enable validation of yield and damage prediction without error in the prediction of crop development.

\section{Visual validation}

Two simulation runs are made for each data set, the first with the leaf area index calculated as the product of the simulated weight of the leaves and constant specific leaf area, the second with the observed leaf area index as input. Results of the latter runs are used to identify errors in the simulation of the still poorly understood leaf area dynamics.

Leaf weight and area dynamics. The observed rate of leaf weight decrease is reproduced by the simulation model during the major part of the grain filling period for all data sets, except for EEST 83 where it is overestimated (Fig. 3). The observed increase in leaf weight for EEST84 which is probably attributable to a nitrogen fertilizer application of $40 \mathrm{~kg}(\mathrm{~N}) \mathrm{ha}^{-1}$ during flowering, is not reproduced by the model since no growth of the leaves after flowering is assumed.

The onset of leaf death is simulated well for EEST84, EEST83, PAGV1 and PAGV2. For BOUWING84, the onset of leaf death is simulated too early, possibly due to an overestimation of initial leaf weight as in four subsequent samples leaf weight was constant but lower than in the initial sample. For PAGV3, the onset is simulated too late.

In the data sets, the specific leaf area decreases in the course of grain ripening by some 10 to $15 \%$ whereas in the model, specific leaf area with constant value of $20 \mathrm{~m}^{2}$ $\mathrm{kg}^{-1}$ is assumed. As a result, the model tends to overestimate leaf area index towards the end of grain filling. 
Table 3. General information on the datasets used to evaluate the crop model and the damage model.

\begin{tabular}{|c|c|c|c|}
\hline & PAGV1 & PAGV2 & PAGV3 \\
\hline Location & : Lelystad & Lelystad & Lelystad \\
\hline Wheat variety & : Arminda & Arminda & Arminda \\
\hline Grain yield $\left(\mathrm{kg} \mathrm{ha}^{-1}\right)$ & $: 6256$ & 7442 & 8279 \\
\hline Soil type & : Sandy loam & Sandy loam & Sandy loam \\
\hline Percentage silt & $: 23$ & 23 & 23 \\
\hline Previous crop & : sugar beets & sugar beets & sugar beets \\
\hline Sowing date & : 25 Oct 1982 & 25 Oct 1982 & 25 Oct 1982 \\
\hline Flowering date & : 22 June 1983 & 22 June 1983 & 22 June 1983 \\
\hline Harvest date & : 2 August 1983 & 2 August 1983 & 2 August 1983 \\
\hline Row spacing (cm) & : 12.5 & 12.5 & 12.5 \\
\hline Sowing density $\left(\mathrm{kg} \mathrm{ha}^{-1}\right)$ & $: 140$ & 140 & 140 \\
\hline Total $\mathrm{N}\left(\mathrm{kg} \mathrm{ha}^{-1}\right)$ & $: 120$ & 200 & 300 \\
\hline Growth regulator & : yes & yes & yes \\
\hline Protective chemicals* & $: \mathrm{H}, \mathrm{F}$ & $\mathrm{H}, \mathrm{F}$ & $\mathrm{H}, \mathrm{F}$ \\
\hline Experimental design & : Random block & Random block & Random block \\
\hline Replicates & $: 8$ & 8 & 8 \\
\hline No. sampling dates & $: 4$ & 4 & 4 \\
\hline \multirow[t]{2}{*}{ Sample size (tillers) } & $: 25$ & 25 & 25 \\
\hline & EEST83 & EEST84 & BOUWING84 \\
\hline Location & : Nagele & Nagele & Randwijk \\
\hline Wheat variety & : Arminda & Arminda & Arminda \\
\hline Grain yield $\left(\mathrm{kg} \mathrm{ha}^{-1}\right)$ & : 4496 & $9290 / 7778^{* * *}$ & $8754 / 8549^{* * *}$ \\
\hline Soil type & : Sandy clay & Sandy clay & Clay \\
\hline Percentage silt & $: 45$ & 33 & $35-60$ \\
\hline Previous crop & : potatoes & sugar beet & potatoes \\
\hline Sowing dat & : 19 Oct 1982 & 4 Nov 1983 & 22 Oct 1983 \\
\hline Flowering date & : 22 June 1983 & 27 June 1984 & 20 June 1984 \\
\hline Harvest date & : 3 august 1983 & 31 August 1984 & 23 August 1984 \\
\hline Row spacing $(\mathrm{cm})$ & $: 15$ & 15 & 24 \\
\hline Sowing density $\left(\mathrm{kg} \mathrm{ha}^{-1}\right)$ & $: 148$ & 148 & 138 \\
\hline Total N $\left(\mathrm{kg} \mathrm{ha}^{-1}\right)$ & : 94 & 250 & 250 \\
\hline Growth regulator & : yes & no & no \\
\hline Protective chemicals* & $: \mathrm{H}, \mathrm{F}, \mathrm{I}$ & $\mathrm{H}, \mathrm{F}, \mathrm{I}^{* *}$ & $\mathrm{H}, \mathrm{F}, \mathrm{I} * *$ \\
\hline Experimental design & : Random block & Random block & Random block \\
\hline Replicates & $: 8$ & 6 & 6 \\
\hline No. sampling dates & $: 4$ & 10 & 9 \\
\hline Sample size (tillers) & $: 25$ & 50 & 50 \\
\hline
\end{tabular}

$* \mathrm{H}=$ herbicide, $\mathrm{F}=$ fungicide, $\mathrm{I}=$ insecticide.

** Insecticide treatment aimed at creating aphid infestations of different intensity.

*** Yield without and with aphids, respectively. The final yields for EEST84 were 8114 and $7907 \mathrm{~kg} \mathrm{ha}^{-1}$ respectively due to delayed harvest. Here, the penultimate yields are shown. 

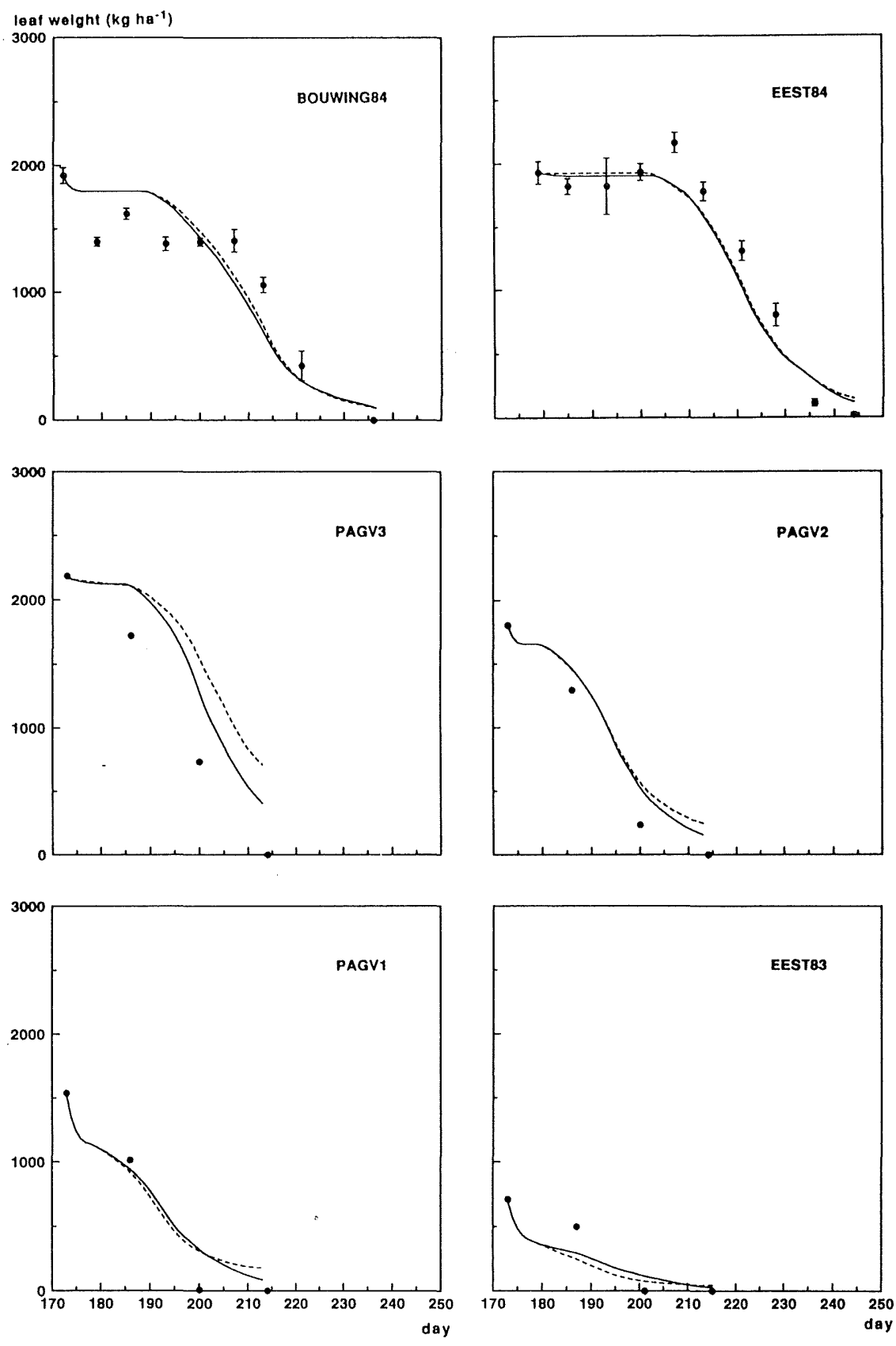

Fig. 3. Observed ( $\bullet$ ) and simulated leaf weight for six data sets. In the model, leaf area index was calculated (------) or introduced as observed (_- Vertical bars represent the standard error of the mean. A description of the data sets is given in Table 3. 
Leaf nitrogen dynamics. The observed rate of decrease of the amount of nitrogen in the green leaves is reproduced by the simulation model (Fig. 4). For EEST84, the model initially underestimates the amount of leaf nitrogen decrease, probably because of the late nitrogen fertilizer application. The nitrogen concentration of the leaves is simulated reasonably well at higher yield levels (not shown). At low yield levels (PAGV1, EEST83), leaf nitrogen concentration initially is overestimated due to underestimation of leaf weight.

Grain yield. The simulated and observed rates of increase of grain yield in the linear phase compare well for all data sets (Fig. 5). Also, the onset of grain filling is predicted accurately. Slight discrepancies between simulated and observed grain yield in the linear growth phase for BOUWING84 are most likely due to an incorrect estimate of the date of flowering caused by the heterogeneous soil conditions at the experimental site.

Simulated and observed grain yields diverge towards the end of grain filling. Using observed values of leaf area index, final grain yield is underestimated for PAGV1, PAGV2, PAGV3 and EEST83. The relative error in grain yield is less than $11 \%$ for PAGV1, PAGV2 and PAGV3 and 19\% for EEST83. In part these discrepancies are due to inconsistencies in the field data: grain yield was reported to increase during the last two weeks before harvest for PAGV1 and EEST 83 while neither green leaves nor green stems were found. For EEST84 and BOUWING84, simulated grain yield is too high at the end of the growing season. This is caused by the absence of a predetermined cessation of grain filling in the model: grain filling continues until the source is exhausted. Using a large set of experimental data, Van Keulen and Seligman (1987) calculated grain filling to cease at 0.72 of the physiological time between flowering and ripeness, on average, due to death of the sieve tubes in the stem and the rachis. Thus, the high leaf area index values for EEST84 and BOUWING84 at the end of the growing season have not contributed to yield as the grains were ripe before the straw. The consequence of a decrease in sink strength for simulated grain yield is evaluated in the sensitivity analysis.

\section{Sensitivity analysis}

Fine sensitivity analysis. Fine sensitivity analysis is carried out for all model parameters using initial conditions of the data sets EEST84 and EEST83. Parameters with high relative sensitivity include the initial light use efficiency of leaves and the rate of carbon dioxide assimilation at light saturation, which determine the size of the carbohydrate source, and parameters determining the sizes of the nitrogen source and sink (Table 4). At the high crop nitrogen level of EEST84, variations in grain, density and potential rate of nitrogen accumulation of grains, which determine the size of the nitrogen sink, have large effects on grain yield as these parameters affect the green area duration. For EEST83, nitrogen levels are so low that green area is dying at maximum rate from flowering. Then changes in the maximum rate of nitrogen uptake and the time constant for nitrogen translocation which determine the size of the nitrogen source, have a larger effect on grain yield than changes in parameters determining the size of the nitrogen sink. 

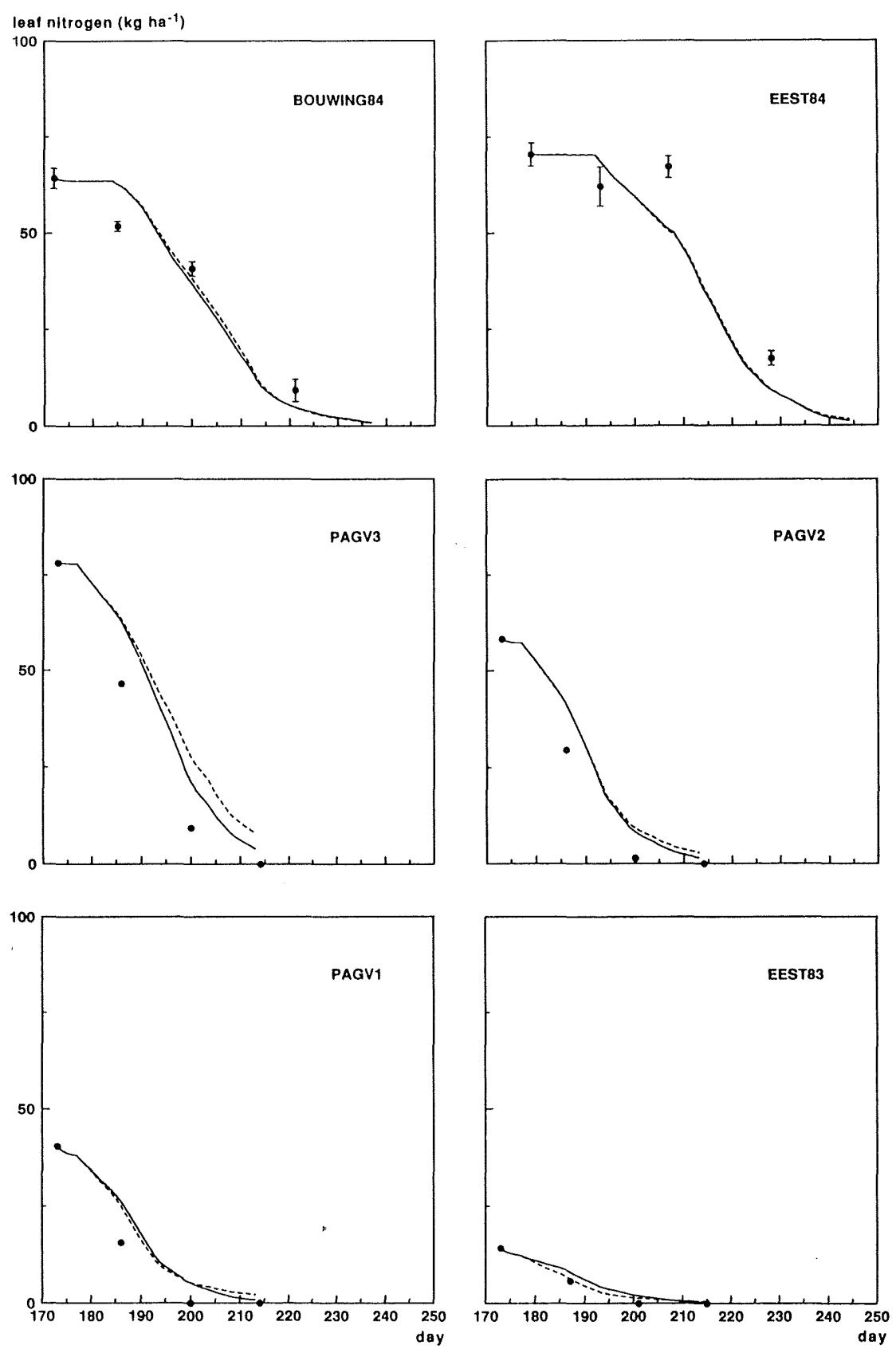

Fig. 4. Observed $(\bullet)$ and simulated amount of leaf nitrogen for six data sets. In the model, leaf area index was calculated (---.----) or introduced as observed (- $(-)$. Vertical bars represent the standard error of the mean. A description of the data sets is given in Table 3. 

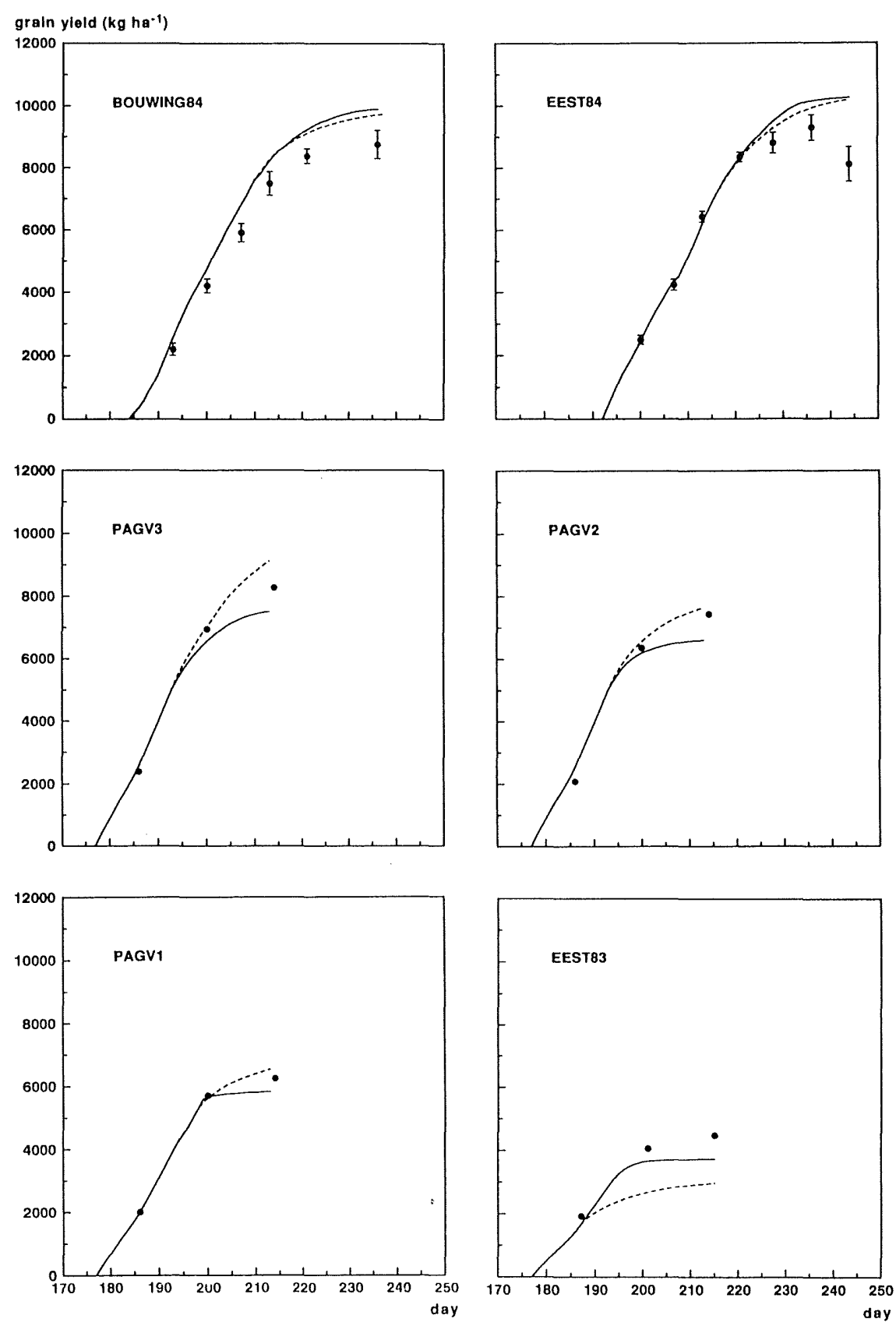

Fig. 5. Observed ( $\bullet$ ) and simulated grain yield for six data sets. In the model, leaf area index was calculated (-------) or introduced as observed (- $\longrightarrow$ ). Vertical bars represent the standard error of the mean. A description of the data sets is given in Table 3. 
Table 4. Relative sensitivity of simulated end-of-season grain yield calculated with the crop model run with data of EEST 84 and EEST 83 for a number of model parameters. In the runs leaf area index is simulated. In the standard version of the model, simulated grain yield is 10187 $\mathrm{kg} \mathrm{ha}^{-1}$ for EEST84 and $2983 \mathrm{~kg} \mathrm{ha}^{-1}$ for EEST83. Relative sensitivity is calculated as the ratio of percentage change in grain weight and percentage change in parameter.

\begin{tabular}{|c|c|c|c|c|c|c|c|}
\hline \multirow[t]{2}{*}{ Parameter } & \multirow[t]{2}{*}{ Unit } & \multicolumn{2}{|c|}{ Reference value } & \multicolumn{2}{|c|}{$\begin{array}{l}\% \text { change in } \\
\text { parameter }\end{array}$} & \multicolumn{2}{|c|}{$\begin{array}{l}\text { Relative } \\
\text { sensitivity }\end{array}$} \\
\hline & & EEST 84 & EEST 83 & EEST 84 & EEST 83 & EEST 84 & EEST83 \\
\hline $\begin{array}{l}\text { Rate of leaf } \mathrm{CO}_{2} \\
\text { assimiliation at } \\
\text { light saturation }\end{array}$ & $\mathrm{kg} \mathrm{ha}^{-1} \mathrm{~h}^{-1}$ & $35^{\mathrm{a}}$ & $35^{\mathrm{a}}$ & $\begin{array}{l}+14 \\
-14\end{array}$ & $\begin{array}{l}+14 \\
-14\end{array}$ & $\begin{array}{l}0.33 \\
0.39\end{array}$ & $\begin{array}{l}0.43 \\
0.50\end{array}$ \\
\hline $\begin{array}{l}\text { Initial efficiency } \\
\text { of light use of } \\
\text { leaves }\end{array}$ & $\begin{array}{l}\mathrm{kg} \mathrm{ha}{ }^{-1} h^{-1} \\
\left(\mathrm{~J} \mathrm{~m}^{-2} \mathrm{~s}^{-1}\right)^{-1}\end{array}$ & $0.45^{\mathrm{b}}$ & $0.45^{\mathrm{b}}$ & $\begin{array}{l}+11 \\
-11\end{array}$ & $\begin{array}{l}+11 \\
-11\end{array}$ & $\begin{array}{l}0.64 \\
0.69\end{array}$ & $\begin{array}{l}0.45 \\
0.51\end{array}$ \\
\hline Grain density & $\mathrm{ha}^{-1}$ & $2.46 \cdot 10^{8 \mathrm{c}}$ & $1.41 \cdot 10^{8 \mathrm{c}}$ & $\begin{array}{l}+8 \\
-\quad 8\end{array}$ & $\begin{array}{l}+8 \\
-\quad 8\end{array}$ & $\begin{array}{l}-0.47 \\
-0.54\end{array}$ & $\begin{array}{l}-0.11 \\
-0.21\end{array}$ \\
\hline $\begin{array}{l}\text { Maximum rate of } \\
\text { soil nitrogen } \\
\text { uptake }\end{array}$ & $k g h a^{-1} d^{-1}$ & $3^{d}$ & $3^{d}$ & $\begin{array}{l}+100 \\
-\quad 67\end{array}$ & $\begin{array}{l}+100 \\
-\quad 67\end{array}$ & $\begin{array}{r}-0.07 \\
0.19\end{array}$ & $\begin{array}{l}0.29 \\
0.22\end{array}$ \\
\hline $\begin{array}{l}\text { Time constant } \\
\text { for nitrogen } \\
\text { translocation }\end{array}$ & $d^{-1}$ & $8^{d}$ & $8^{d}$ & $\begin{array}{l}+100 \\
-50\end{array}$ & $\begin{array}{l}+100 \\
-50\end{array}$ & $\begin{array}{l}0.06 \\
0.12\end{array}$ & $\begin{array}{l}0.21 \\
0.27\end{array}$ \\
\hline $\begin{array}{l}\text { Potential rate of } \\
\text { nitrogen accumu- } \\
\text { lation of grains }\end{array}$ & $k g h a^{-1} d^{-1}$ & table ${ }^{b}$ & table ${ }^{b}$ & $\begin{array}{l}+10 \\
-10\end{array}$ & $\begin{array}{l}+10 \\
-10\end{array}$ & $\begin{array}{l}-0.47 \\
-0.55\end{array}$ & $\begin{array}{l}-0.12 \\
-0.21\end{array}$ \\
\hline
\end{tabular}

a Basically from Van Keulen \& Seligman (1987), calibrated on datasets PAGV1 and EEST84.

b Van Keulen \& Seligman (1987).

c Input.

${ }^{d}$ Groot (1987).

Table 5. Simulated grain yield $\left(\mathrm{kg} \mathrm{ha}^{-1}\right)$ in the standard version of the crop model ('standard run') and simulated grain yield assuming grain filling to end at 0.72 of the time between flowering and ripeness ('sink limitation'). Leaf area index is simulated.

\begin{tabular}{lllc}
\hline Dataset & \multicolumn{2}{l}{ Simulated grain yield } & Observed grain yield \\
\cline { 2 - 3 } & standard run & sink limitation & \\
EEST84 & 10187 & 9653 & $9290 / 8114^{1}$ \\
BOUWING84 & 9727 & 9186 & 8754 \\
PAGV3 & 9120 & 7673 & 8279 \\
PAGV2 & 7650 & 6938 & 7442 \\
PAGV1 & 6541 & 5952 & 6256 \\
EEST83 & 2983 & 2810 & 4496 \\
\hline
\end{tabular}

${ }^{1}$ Penultimate and ultimate yield, respectively (see footnote Table 3 ). 
Coarse sensitivity analysis. By removing the ear layer from the calculation of carbon dioxide assimilation simulated grain yield of EEST84 increases by $1 \%$ due to higher light intensities in the leaf layer.

Cessation of grain filling at 0.72 of the time between flowering and ripeness causes considerable reduction of simulated grain yield except for EEST 83 where most of the green area is already dead by this time due to nitrogen shortage (Table 5).

Analysis of errors in inputs

The $q$-values for grain yield of EEST84 and BOUWING84 are shown in Table 6. Other data sets could not be evaluated due to lack of information on sampling error. Estimated errors in grain density, average daily temperature and flowering date cause major changes in output. Values of $q$ increase towards the end of the growing season. Only the final $q$-value for EEST84 exceeds the limit of 2.

\section{Discussion of the crop model}

The major output of the model, grain yield, is simulated reasonably well: both onset and rate of grain filling are predicted accurately until the onset of source-limited growth: During source-limited growth, the amount of photosynthetically active tissue determines the rate of grain filling and errors in the simulation of leaf area index become apparent. The evaluation points to a lack of understanding of the processes involved in leaf death, which becomes especially prominent at low crop nitrogen levels. In the model, leaf death rate is calculated by comparing the actual nitrogen concentra-

Table 6. Results of crop model input error analysis per sampling date (Julian day) for EEST84 and BOUWING84. SEM is standard error of the mean. For explanation of symbols see text.

\begin{tabular}{|c|c|c|c|c|c|}
\hline \multicolumn{6}{|c|}{ EEST84 } \\
\hline day & $z_{\mathrm{s}}$ & $\sqrt{ }\left(E\left(\operatorname{var} z_{\mathrm{s}}\right)\right)$ & $z_{0}$ & $\operatorname{SEM}\left(z_{0}\right)$ & $q$ \\
\hline 200 & 2442 & 280 & 2499 & 143 & -0.18 \\
\hline 207 & 4344 & 373 & 4243 & 177 & 0.24 \\
\hline 213 & 6178 & 512 & 6432 & 172 & -0.47 \\
\hline 221 & 8262 & 167 & 8350 & 158 & -0.38 \\
\hline 228 & 9276 & 289 & 8806 & 331 & 1.07 \\
\hline 236 & 9918 & 421 & 9290 & 414 & 1.06 \\
\hline 244 & 10187 & 491 & 8114 & 559 & 2.79 \\
\hline \multicolumn{6}{|c|}{ BOUWING84 } \\
\hline day & $z_{\mathrm{s}}$ & $\sqrt{ }\left(E\left(\operatorname{var} z_{\mathrm{s}}\right)\right)$ & $z_{0}$ & $\operatorname{SEM}\left(z_{0}\right)$ & $q$ \\
\hline 193 & 2536 & 521 & 2202 & 197 & 0.60 \\
\hline 200 & 4736 & 661 & 4213 & 224 & 0.75 \\
\hline 207 & 6814 & 762 & 5913 & 293 & 1.10 \\
\hline 213 & 8259 & 194 & 7504 & 380 & 1.77 \\
\hline 221 & 9116 & 431 & 8385 & 239 & 1.48 \\
\hline 237 & 9727 & 702 & 8754 & 461 & 1.16 \\
\hline
\end{tabular}

Neth. J. Pl. Path. 97 (1991) 
tion in the leaves to a maximum concentration found in experiments with high nitrogen fertilizer input. At low nitrogen supply this may be incorrect as many processes adapt to the nitrogen history of the crop.

Compared to the penultimate harvest, grain yield decreases drastically at the final harvest for EEST84. This may constitute respiratory loss due to delayed harvesting, as the crop was still partly green at the scheduled harvest time and had to be killed with herbicide.

\section{The damage model}

\section{Data for validation}

The data sets EEST84 and BOUWING84 comprise crop growth analysis data of an experiment with grain aphid infestations of different size and duration (Rossing and Van de Wiel, 1990). For validation of the damage model the data pertaining to the largest infestation are used. For EEST84, the aphid infestation caused a significant reduction of grain yield, leaf area index, leaf weight and amount of leaf nitrogen during the major part of the post-anthesis period. For BOUWING84, few significant effects were found due to the smaller aphid infestation and the heterogeneous soil conditions (river clay on sand) (Rossing and Van de Wiel, 1990). In the validation runs leaf area index is simulated.

Preliminary model runs showed that differences between hypotheses I and II or III and IV describing the direct effects of the grain aphid (Fig. 1) are small as aphid load is low after onset of source-limited growth for both EEST84 and BOUWING84. Therefore, the validation focuses on hypotheses I and IV.

\section{Visual validation}

Leaf weight dynamics. Both the onset and the rate of decrease of leaf weight in the infested crop of EEST 84 are reproduced by the simulation model when the uptake of phloem sap by the aphids is compensated for by an increased demand (hypothesis I), which causes accelerated depletion of translocatable nitrogen in vegetative organs (Fig. 6). For BOUWING84, the simulated onset of leaf death is too early and, initially, the rate of leaf death is overestimated, similar to the results of the aphid-free control (cf. Fig. 3). For both EEST84 and BOUWING84, the simulated reduction of leaf weight compared to the aphid-free control is less than the observed reduction, indicating that factors contribute to leaf death which have not been taken into consideration in the model.

Amount of leaf nitrogen. The onset but not the size of the observed reduction of leaf ritrogen is reproduced by the simulation model when compensation for aphid feeding by increased demand is assumed (hypothesis I, Fig. 7). For EEST84, the simulated onset of leaf nitrogen decrease is too early, similar to the results for the aphid-free control where it has been attributed to a late nitrogen fertilizer application.

Grain yield. For EEST84, the onset of aphid damage and the rate of grain yield increase during the linear phase are reproduced well by the damage model when compensation for aphid feeding by increased demand is absent (hypothesis IV, Fig. 8). Final grain yield is overestimated slightly. When compensation for aphid feeding 

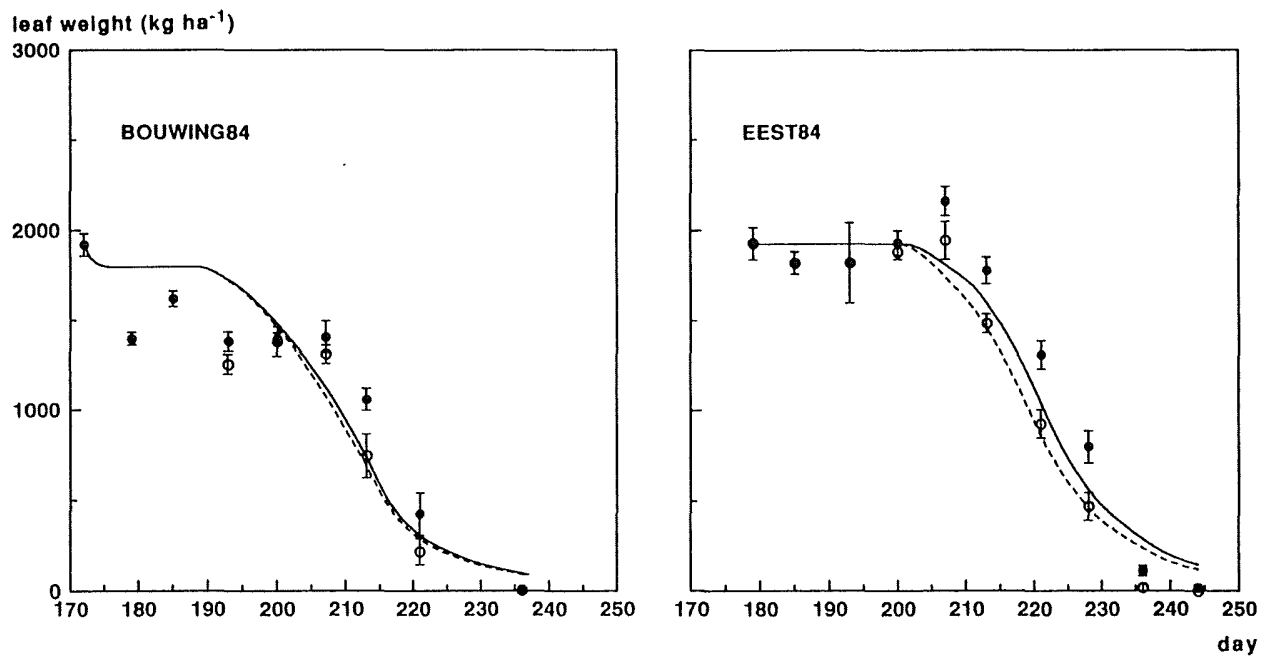

Fig. 6. Observed and simulated leaf weight of EEST84 and BOUWING84 based on hypotheses I and IV to describe the direct effects of Sitobion avenae. Vertical bars represent standard errors of the mean. Observed grain yield of the control $(\bullet)$ and the most severely infested treatment (०). Simulated grain yield without aphids ( ) and with an infestation as observed in the most severely infested treatment (-..---) based on hypothesis I. Simulated results based on hypothesis IV are identical to simulated leaf weight without aphids. Leaf area index is simulated.
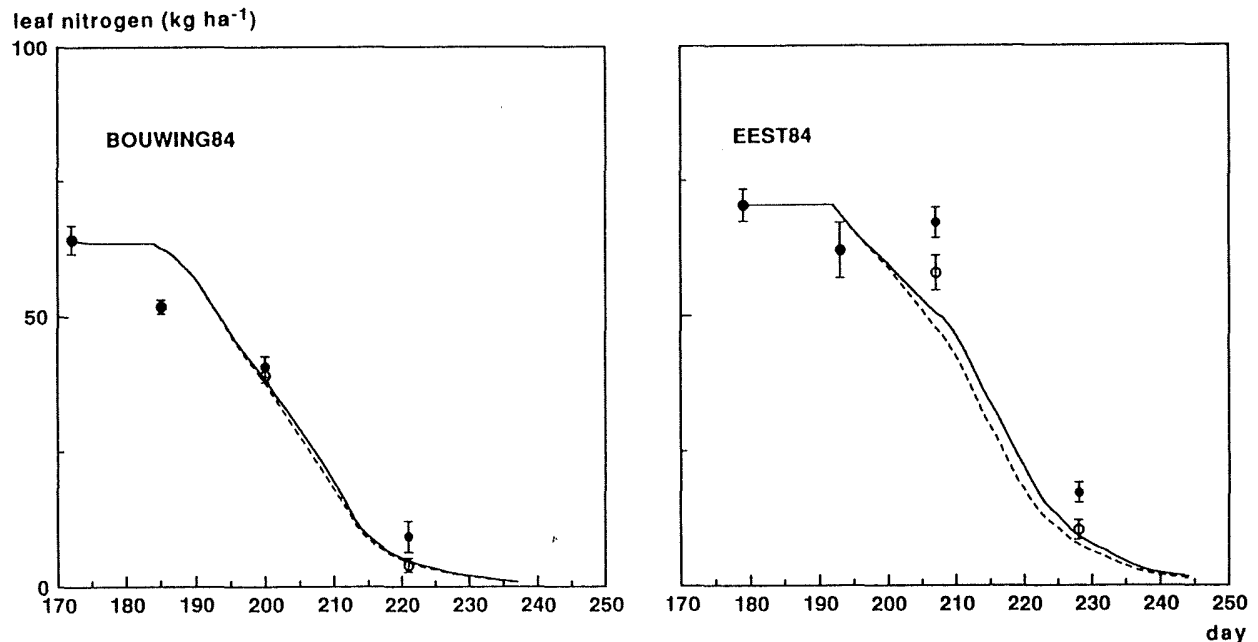

Fig. 7. Observed and simulated amount of leaf nitrogen of EEST84 and BOUWING84 based on hypotheses I and IV to describe the direct effects of Sitobion avenae. Vertical bars represent standard errors of the mean. Observed grain yield of the control $(\bullet)$ and the most severely infested treatment $(0)$. Simulated grain yield without aphids ( ) and with an infestation as observed in the most severely infested treatment (--------) based on hypothesis I. Simulated results based on hypothesis IV are identical to simulated leaf nitrogen without aphids. Leaf area index is simulated.

Neth. J. Pl. Path. 97 (1991) 

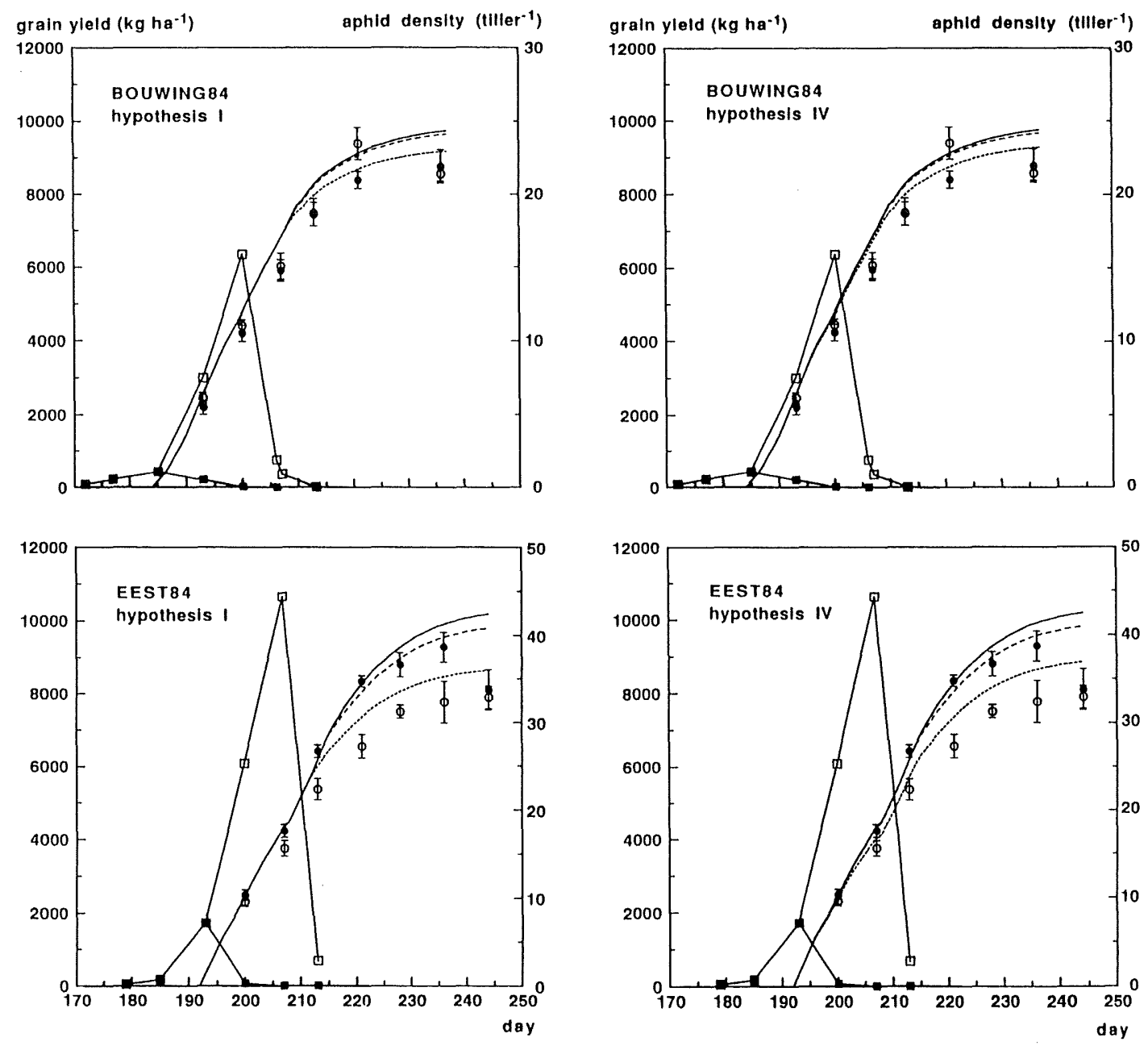

Fig. 8. Observed and simulated grain yield of EEST 84 and BOUWING84 based on hypotheses I and IV to describe the direct effects of Sitobion avenae. Vertical bars represent standard errors of the mean. Observed grain yield of the control $(\bullet)$ and the most severely infested treatment (०). Simulated grain yield without aphids (_- ), and with aphid infestations as observed in the control treatment (-- $)$ and in the most severely infested treatment (-------), respectively. The size of the aphid infestations is shown for the control $(\longrightarrow-)$ and the most severe infestation $(\longrightarrow-$. Leaf area index is simulated.

by increased demand is assumed (hypothesis I), damage becomes apparent when the process of grain filling changes from sink-limited to source-limited (day 212 for EEST84 and day 210 for BOUWING84). For BOUWING84, the simulation model predicts little damage during the major part of the growing season in agreement with the experimental data. Final damages simulated with hypotheses I and IV differ approximately $200 \mathrm{~kg} \mathrm{ha}^{-1}$ for EEST84 and $70 \mathrm{~kg} \mathrm{ha}^{-1}$ for BOUWING84. 


\section{Sensitivity analysis}

Fine sensitivity analysis. Fine sensitivity analysis is carried out with data of the aphid-infested plots of EEST84, using hypotheses I and IV to model the direct effects of aphids. Relative sensitivity is expressed in terms of grain yield and in terms of damage. The largest changes in output (Table 7) result from perturbation of the rate of phloem sap uptake as it determines the size of direct as well as indirect effects. Changes in the parameters describing the effect of honeydew on leaf carbon dioxide assimilation have a significantly smaller effect. The differences in relative sensitivities between hypotheses I and IV are small.

Table 7. Relative sensitivity of end-of-season grain yield for a number of model parameters calculated with the damage model run with data of EEST84. In the runs leaf area index is simulated. Simulted grain yield in the absence of aphids is $10187 \mathrm{~kg} \mathrm{ha}^{-1}$. Simulated grain yield in the presence of aphids is $8655 \mathrm{~kg} \mathrm{ha}^{-1}$ and $8864 \mathrm{~kg} \mathrm{ha}^{-1}$ for hypotheses I and IV, respectively. Relative sensitivity is calculated as the ratio of percentage change in simulated grain yield or simulated damage and percentage change in parameter value.

\begin{tabular}{|c|c|c|c|c|c|c|c|}
\hline \multirow[t]{3}{*}{ Parameter } & \multirow[t]{3}{*}{ Unit } & \multirow{3}{*}{$\begin{array}{l}\text { Reference } \\
\text { value }\end{array}$} & \multirow{3}{*}{$\begin{array}{l}\% \\
\text { change } \\
\text { in } \\
\text { param- } \\
\text { eter }\end{array}$} & \multicolumn{4}{|c|}{ Relative sensitivity } \\
\hline & & & & \multicolumn{2}{|c|}{ hypothesis I } & \multicolumn{2}{|c|}{ hypothesis IV } \\
\hline & & & & yield & damage & yield & damage \\
\hline $\begin{array}{l}\text { Phloem sap uptake } \\
\text { rate }\end{array}$ & $\mathrm{kg} \mathrm{mg}^{-1} \mathrm{~d}^{-1}$ & $8.9 \times 10^{-9} \mathrm{~A}$ & $\begin{array}{l}+10 \\
-10\end{array}$ & $\begin{array}{l}-0.11 \\
-0.12\end{array}$ & $\begin{array}{l}0.63 \\
0.68\end{array}$ & $\begin{array}{l}-0.09 \\
-0.09\end{array}$ & $\begin{array}{l}0.60 \\
0.63\end{array}$ \\
\hline $\begin{array}{l}\text { Extinction coefficient } \\
\text { for honeydew }\end{array}$ & - & $0.8^{\mathrm{B}}$ & -25 & -0.00 & 0.03 & -0.00 & 0.3 \\
\hline $\begin{array}{l}\text { Fraction of honeydew } \\
\text { deposited on ears }\end{array}$ & - & $0.3^{\mathrm{C}}$ & $\begin{array}{l}+33 \\
-33\end{array}$ & $\begin{array}{l}0.00 \\
0.00\end{array}$ & $\begin{array}{l}-0.03 \\
-0.00\end{array}$ & $\begin{array}{l}0.00 \\
0.00\end{array}$ & $\begin{array}{l}-0.02 \\
-0.01\end{array}$ \\
\hline $\begin{array}{l}\text { Maximum relative } \\
\text { reduction of } P_{\mathrm{m}}\end{array}$ & - & $0.24^{\mathrm{D}}$ & $\begin{array}{l}+20 \\
-20\end{array}$ & $\begin{array}{l}-0.05 \\
-0.05\end{array}$ & $\begin{array}{l}0.31 \\
0.30\end{array}$ & $\begin{array}{l}-0.06 \\
-0.06\end{array}$ & $\begin{array}{l}0.39 \\
0.38\end{array}$ \\
\hline $\begin{array}{l}\text { Maximum relative } \\
\text { increase of } R_{\mathrm{d}}\end{array}$ & - & $0.35^{\mathrm{D}}$ & $\begin{array}{l}+20 \\
-20\end{array}$ & $\begin{array}{l}-0.04 \\
-0.04\end{array}$ & $\begin{array}{l}0.21 \\
0.20\end{array}$ & $\begin{array}{l}-0.04 \\
-0.04\end{array}$ & $\begin{array}{l}0.27 \\
0.27\end{array}$ \\
\hline
\end{tabular}

\footnotetext{
A After Rabbinge \& Coster (1984).

B This paper.

C Vereijken (1979).

D Rossing \& Van de Wiel (1990).
}

Coarse sensitivity analysis. In the coarse sensitivity analysis the contributions of the injury components aphid feeding, honeydew reducing the rate of carbon dioxide assimilation at light saturation and honeydew increasing maintenance respiration to total damage are calculated. For this purpose, damage due to feeding only and damage due to feeding and increased maintenance respiration are compared to total simulated damage. Secondly, the potential effect of rain and leaf saprophytes on grain yield is evaluated. The analysis is carried out with data of the aphid-infested plots of EEST84. 
Table 8. Total damage and contribution of injury components for EEST84, simulated under different hypotheses on the partitioning of phloem sap between $S$. avenae and grains. The size of the aphid sink is calculated assuming a demand for nitrogen. For explanation of the hypotheses see Fig. 1.

\begin{tabular}{lllll}
\hline Hypothesis & $\begin{array}{l}\text { Total damage } \\
\mathrm{kg} \mathrm{ha}^{-1}\end{array}$ & \multicolumn{2}{l}{ Injury components } \\
\cline { 3 - 4 } & & feeding & $\begin{array}{l}\text { photos. } \\
\text { reduction } \\
(\%)\end{array}$ & $\begin{array}{l}\begin{array}{l}\text { respiration } \\
\text { increase } \\
(\%)\end{array} \\
\text { I }\end{array}$ \\
II & 1532 & $(\%)$ & & \\
III & 1543 & 51 & 28 & 21 \\
IV & 1251 & 51 & 28 & 21 \\
& 1323 & 35 & 37 & 28 \\
\hline
\end{tabular}

Aphid feeding constitutes the most important cause of damage for hypotheses I and II while the three components contribute equally to total damage when aphids do not affect the flow rate of phloem sap (hypotheses III and IV) (Table 8).

The dynamic contribution of each injury component to total simulated damage for EEST84 is represented in Fig. 9. For hypothesis I, damage is apparent from the time simulated grain growth becomes source-limited (day 212), three days before the carbo-
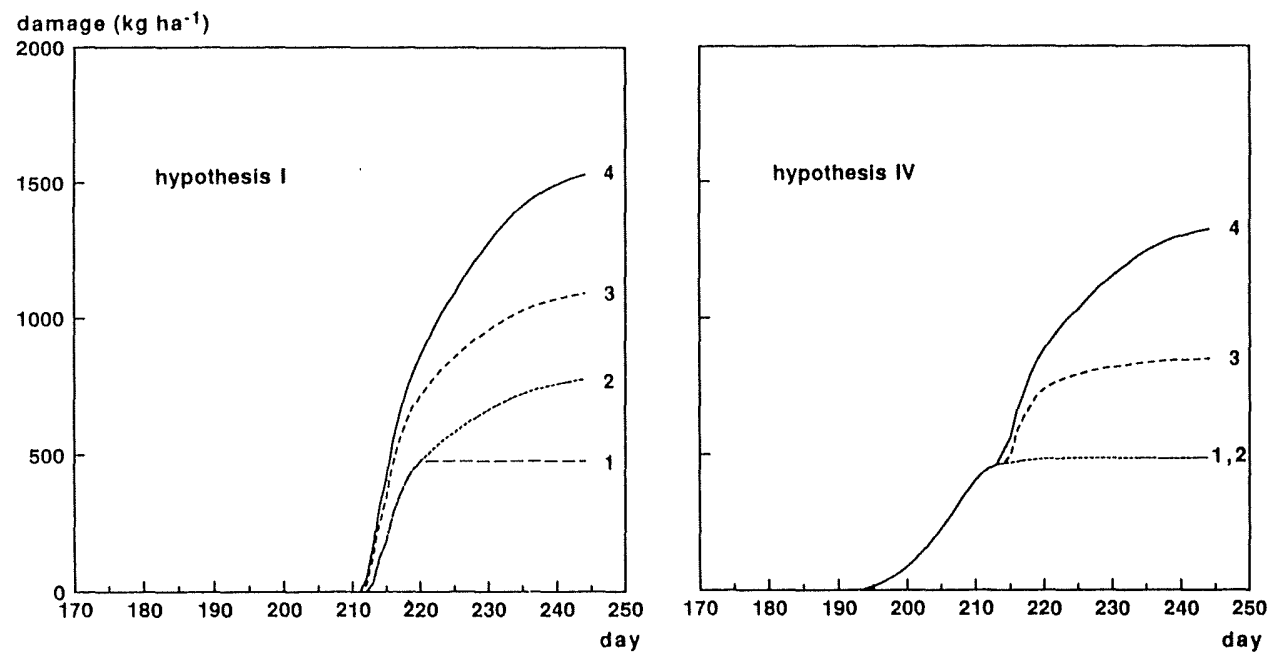

Fig. 9. Simulated total damage $\left(\mathrm{kg} \mathrm{ha}^{-1}\right)$ and damage components for EEST84, the most severe aphid infestation. Simulation runs are based on hypotheses I and IV to describe the direct effects of $S$. avenae.

1: carbohydrate uptake.

2: carbohydrate and nitrogen uptake.

3: carbohydrate and nitrogen uptake + increased maintenance respiration.

4: carbohydrate and nitrogen uptake + increased maintenance respiration + decreased carbon dioxide assimilation at light saturation. 
hydrate reserves are depleted in the run without aphids. Simulated damage due to each injury component increases with time. The increase of feeding damage after aphid density has become zero (day 221), is caused by enhanced depletion of translocatable nitrogen during feeding, later in the season resulting in lower carbon dioxide assimilation rates and increased death rates of non-grain organs. This accounts for $37 \%$ of the total direct damage.

In the model based on hypothesis IV simulated damage is apparent from grain set onward since the demand of the grains is only partly met as a result of aphid feeding (Fig. 9). Simulated damage due to feeding does not increase after departure of the aphids from the crop, as the rate of nitrogen depletion is not affected by feeding, contrary to the model based on hypothesis I.

So far, it has been assumed that, once present, honeydew remains on the plant. However, weather and saprophytic micro-organisms can reduce the amount of honeydew per unit area (Fokkema et al., 1983). Quantitative relations are lacking. The effect of rain on damage due to honeydew is evaluated by assuming complete removal of honeydew and its effects after a daily precipitation intensity equal to or exceeding 5 $\mathrm{mm}$, which occurred on day 190 to 193 and 197 for EEST84. The effect on simulated yield is an increase of less than $1 \%\left(42 \mathrm{~kg} \mathrm{ha}^{-1}\right)$.

Saprophytic leaf fungi have been reported to affect the net rate of carbon dioxide assimilation of leaves in two ways. During a few days after honeydew deposition onto a leaf, stimulation of leaf micro-organisms causes an increase in the rate of dark respiration of the plant (Smedegaard-Petersen, 1982; Rossing and Van de Wiel, 1990). The effect is ascribed to plant defense reactions to penetration attempts by saprophytic fungi (Smedegaard-Petersen, 1982). In the longer term, saprophytic phyllosphere micro-organisms, especially the black molds, may increase to such densities that they intercept light, thus reducing the initial light use efficiency (Vereijken, 1979; Rabbinge et al., 1981; Rossing and Van de Wiel, 1990). The quantitative consequences of these effects of leaf saprophytes on leaf carbon dioxide assimilation for grain yield can be evaluated with the simulation model.

The short-term effects of saprophytic micro-organisms on grain yield are evaluated by adapting the damage model to include an increase in the rate of maintenance respiration one day after honeydew deposition. Respiration increases in proportion to the rate of honeydew deposition with a maximum of $47 \%$ of the control after deposition of $2.6 \mathrm{~g} \mathrm{~m}^{-2}$ day $^{-1}$ (data of Rossing and Van de Wiel, 1990; see also SmedegaardPetersen, 1982), followed by a linear decline to normal values after 3,5 or 7 days. These intervals represent the period of time for return to normal values reported by Rossing and Van de Wiel (1990) working with honeydew on winter wheat plants in the field and Smedegaard-Petersen (1982) working with barley plants inoculated with Alternaria alternata and Cladosporium herbarum in the laboratory. The results show that the additional reduction of simulated grain yield as compared to the standard version of the damage model varies from $130 \mathrm{~kg} \mathrm{ha}^{-1}$ to $275 \mathrm{~kg} \mathrm{ha}^{-1}$.

The longer-term effect of leaf saprophytes on grain yield is evaluated assuming damage to be the result of two injury components: aphid feeding and reduction of the initial light use efficiency. The reduction of the initial light use efficiency is proportional to the amount of honeydew deposited and increases linearly with time, starting at zero on the day of deposition. No response is allowed above the maximum reduction of $17 \%$ compared to the control, measured concomitant with a leaf coverage of 2.6

Neth. J. Pl. Path. 97 (1991) 
Table 9. Results of input error analysis of the damage model per sampling date (Julian day) for EEST84 and BOUWING84 using hypothesis IV to describe the direct effects of S. avenae. SEM is standard error of the mean. For explanation of symbols see text.

\begin{tabular}{lrllll}
\hline EEST84 & & & & & \\
\hline day & $z_{\mathrm{s}}$ & $\sqrt{ }\left(E\left(\right.\right.$ var $\left.\left.z_{\mathrm{s}}\right)\right)$ & $z_{\mathrm{o}}$ & $\operatorname{SEM}\left(z_{\mathrm{o}}\right)$ & $q$ \\
200 & 2354 & 279 & 2324 & 138 & 0.10 \\
207 & 4043 & 369 & 3758 & 212 & 0.67 \\
213 & 5714 & 407 & 5378 & 296 & 0.67 \\
221 & 7392 & 212 & 6571 & 325 & 2.00 \\
228 & 8163 & 284 & 7515 & 179 & 1.93 \\
236 & 8657 & 378 & 7778 & 575 & 1.28 \\
244 & 8864 & 427 & 7907 & 309 & 1.81 \\
& & & & & \\
BOUWING84 & & & & & \\
\hline day & $z_{\mathrm{s}}$ & $\sqrt{ }\left(E\left(\right.\right.$ var $\left.\left.z_{\mathrm{s}}\right)\right)$ & & & \\
& & & & & \\
193 & 2515 & 519 & 2447 & 144 & 0.11 \\
200 & 4651 & 658 & 6428 & 155 & 0.33 \\
207 & 6674 & 731 & 7455 & 354 & 1.42 \\
213 & 7974 & 203 & 9383 & 441 & -1.07 \\
221 & 8738 & 415 & 8549 & 199 & 1.08 \\
237 & 9258 & 624 & & & \\
\hline
\end{tabular}

$\mathrm{g}$ (honeydew) $\mathrm{m}^{-2}$ (Rossing and Van de Wiel, 1990). The results show that reduction of the initial light use efficiency decreases simulated yield by approximately $450 \mathrm{~kg}$ $\mathrm{ha}^{-1}$.

\section{Analysis of errors in inputs}

In comparison with the crop model, aphid density is an additional source of input error. The results of the calculation of model error variances and $q$-values (Table 9) show that $q$-values remain within acceptable limits.

Discussion of the damage model

Parameterization. The large effect of the rate of uptake of phloem sap on simulated yield and damage calls for accurate parameter estimates. In a review of honeydew production rates for various aphid-host combinations from which phloem sap uptake rates are calculated, Coster (1983) found his values for S. avenae on spring wheat cv. Bastion which are used in the present damage model, to be within the published range and very close to those found for the same aphid species on spring wheat cv. Opal by Rabbinge et al. (1981). Spiller and Llewellyn (1987) found considerably lower rates for honeydew production by $M$. dirhodum on seedlings of spring wheat (DC 10-11). The difference is possibly caused by a higher nitrogen content of the phloem sap of the seedlings (Van Keulen and Seligman, 1987). 
The submodel describing the distribution of honeydew over the canopy profile has not been compared to field data. However, fine sensitivity analysis showed that neither the value of the extinction coefficient for honeydew nor the partitioning of honeydew between ears and leaves is of major significance to yield and damage.

Formulation of the effect of grain aphid feeding on crop growth processes. The alternative hypotheses on the mode of interaction between aphids and grains do not result in major changes in simulated final grain yield of EEST84 (Table 8). However, the observed onset and the time-course of reduction of grain yield of EEST 84 is simulated correctly only when aphids are assumed not to increase the size of the sinks for nitrogen and carbohydrates (hypotheses III and IV). Thus, compensation for aphid feeding by increased phloem sap flow to the grains (hypotheses I and II) is unlikely to be important. This conclusion is corroborated by results of Vereijken (1979) who found damage by $S$. avenae in two field experiments to agree with the damage expected from the efficiency of food utilization by the aphids. In the experiments, the crop was treated with fungicide to preclude effects of leaf saprophytes. As a consequence, the accelerated leaf death observed in the aphid-infested plots of EEST84 must be due to other causes than aphid feeding. Both honeydew and saprophytic leaf fungi have been reported to decrease green leaf weight (Vereijken, 1979; Rabbinge et al., 1981; Rossing and Van de Wiel, 1990) and leaf nitrogen amount (Rossing and Van de Wiel, 1990). These effects appear to depend on weather conditions, especially humidity and temperature but quantitative relations are lacking.

Contribution of assimilate uptake by the grain aphid to damage. Using hypotheses III and IV, the contribution of aphid feeding to total simulated damage is ca. $35 \%$ for EEST84 (Table 8). Vereijken (1979) and Rabbinge and Vereijken (1980) estimated the direct effect of cereal aphids to be $45-50 \%$ of the total damage while Rabbinge et al. (1983) approximated it to be $16 \%$ at attainable yield levels over $6500 \mathrm{~kg} \mathrm{ha}^{-1}$.

Contribution of short-term increase of dark respiration by leaf saprophytes to damage. The sensitivity analysis showed that even for the relatively large infestation of EEST84, a short-term increase in the rate of dark respiration of leaves is not likely to contribute significantly to damage as has been suggested (Smedegaard-Petersen and Tolstrup, 1985 and references therein). Only at extremely high aphid densities, significant damage may occur. An example is found in experiments of Vereijken (1979) who created aphid infestations in winter wheat with peak densities of approximately 150 $\operatorname{tiller}^{-1}$ ( $S$. avenae only) by placing nylon gauze cages in the crop and introducing aphids. Due to the dry weather during these experiments honeydew crystallized rapidly, precluding long-term effects of saprophytic fungi. Fungicide sprays reduced damage by $50 \%$, most likely by reducing the short-term effects. Under field conditions in the Netherlands, however, densities of uncontrolled cereal aphid populations seldom exceed 30 tiller $^{-1}$.

Effect of weather conditions on the contribution of honeydew to damage. Assuming suitable cool and humid weather conditions, simulated damage due to reduction of the initial light use efficiency by honeydew-stimulated leaf saprophytes is $450 \mathrm{~kg} \mathrm{ha}^{-1}$ for the aphid-infested plots of EEST84. With the standard version of the model, 
honeydew per se has been found to contribute $c a 760 \mathrm{~kg} \mathrm{ha}^{-1}$ to total damage. Thus, model calculations indicate that under hot and dry conditions grain aphid damage is larger as compared to cool and humid conditions, due to a larger contribution of honeydew to damage. Considering the size of the potential effect on yield and the uncertainty in the available information, the relation between weather conditions and the effect of honeydew on leaf carbon dioxide assimilation deserves more attention.

\section{Conclusion}

The model described integrates knowledge of effects of $S$. avenae on growth processes of winter wheat from flowering to ripeness to explain the consequences of an aphid infestation for grain yield. Similar approaches have been adopted to analyze damage by other pests (e.g. brown plant hopper (Nilaparvata lugens (Stal)) in rice (Kenmore, 1980)), by diseases (e.g. powdery mildew (Erysiphe graminis D.C. ex Mérat) on winter wheat (Daamen and Jorritsma, 1990a,b)), by weeds (e.g. barnyard grass (Echinochloa crus-galli (L.) P.B. in maize (Spitters, 1989)), and abiotic causes (e.g. $\mathrm{SO}_{2}$ in faba bean (Kropff, 1989)).

The development of the grain aphid - winter wheat model has served the purpose of organizing existing information and has enabled quantitative evaluation of alternative submodels in cases where little information on processes is available. Components of the grain aphid - winter wheat system which require more attention include the description of processes involved in leaf death at low crop nitrogen levels and the relation between weather variables and the longer term effects of honeydew on leaf carbon dioxide assimilation. Further validation of the model with data sets of different years and locations is desirable.

In spite of the gaps in knowledge identified, the accuracy of the damage model may be sufficient for use in supervised control advisory systems like EPIPRE (Drenth et al., 1989). In practice only low aphid densities are tolerable due to the low costs of chemical control so that errors in the estimation of weather-dependent honeydew damage will remain below the level of detectability. An analysis of the accuracy of the damage model when used for the purpose of decision support is presented elsewhere (Rossing, 1991).

\section{Acknowledgements}

Thanks are due to Rob Groot, Herman van Roermund, Nicoline Roozen and Erna van de Wiel who contributed to the development of the damage model and to dr D.I. Rouse, prof. dr R. Rabbinge, dr ir W. van der Werf and prof. dr J.C. Zadoks for comments on earlier versions of the manuscript.

\section{Appendix I. Modelling the partitioning of phloem sap between grains and aphids}

The hypotheses I to IV are translated into terms of the crop model. The equations pertain to both nitrogen and carbohydrates. A total demand $\left(d_{\mathrm{tot}}\right)$ is defined. For the hypotheses I and II the total demand consists of the sum of the demands of grains and aphids:

$$
d_{\mathrm{tot}}=d_{\mathrm{g}}+d_{\mathrm{a}}
$$


with $d_{\text {tot }}=$ potential rate of carbohydrate or nitrogen accumulation in grains and aphids $(\mathrm{kg}$ ha $\left.\mathrm{a}^{-1} \mathrm{day}^{-1}\right), d_{\mathrm{g}}=$ potential rate of carbohydrate or nitrogen accumulation in the grains $(\mathrm{kg}$ $\left.\mathrm{ha}^{-1} \mathrm{day}^{-1}\right), d_{\mathrm{a}}=$ potential rate of carbohydrate or nitrogen accumulation in the aphids $(\mathrm{kg}$ ha ${ }^{-1}$ day $^{-1}$ ).

For the hypotheses III and IV the total demand consists of the demand of the grains and, before grain set, the demand of the aphids.

$$
d_{\mathrm{tot}}= \begin{cases}d_{\mathrm{a}} & D<0.11 \\ d_{\mathrm{g}} & D \geq 0.11\end{cases}
$$

with $D=$ crop development stage, with $D=0$ at flowering and $D=1$ at ripeness and $\mathrm{d} D / \mathrm{d} t$ a linear function of temperature.

The sink-source concept of the crop model is expressed as:

$$
f_{\mathrm{tot}}=\min \left(d_{\mathrm{tot}}, s_{\mathrm{tot}}\right)
$$

with $f_{\text {tot }}=$ the actual flow of nitrogen or carbohydrate to grains and aphids $\left(\mathrm{kg} \mathrm{ha}^{-1} \mathrm{day}^{-1}\right)$, $s_{\text {tot }}=$ the potential rate of nitrogen or carbohydrate supply to grains and aphids $\left(\mathrm{kg} \mathrm{ha}^{-1}\right.$ day $^{-1}$ ).

The partitioning of $f_{\text {tot }}$ over the sinks depends on the assumption on the nature of the interaction between aphids and grains. In the hypotheses I and III the partitioning is proportional to the demand:

$$
\begin{aligned}
& f_{\mathrm{a}}=d_{\mathrm{a}} / d_{\mathrm{tot}} \cdot f_{\mathrm{tot}} \\
& f_{\mathrm{g}}=d_{\mathrm{g}} / d_{\mathrm{tot}} \cdot f_{\mathrm{tot}}
\end{aligned}
$$

where $f_{\mathrm{a}}=$ actual flow of nitrogen or carbohydrate to the aphids $\left(\mathrm{kg} \mathrm{ha}^{-1} \mathrm{day}^{-1}\right), f_{\mathrm{g}}=$ actual flow of nitrogen or carbohydrate to the grains $\left(\mathrm{kg} \mathrm{ha}^{-1} \mathrm{day}^{-1}\right)$.

If priority is given to the aphids as in hypotheses II and IV, the model becomes:

$$
\begin{aligned}
& f_{\mathrm{a}}=\min \left(d_{\mathrm{a}}, f_{\mathrm{tot}}\right) \\
& f_{\mathrm{g}}=\max \left(f_{\mathrm{tot}}-d_{\mathrm{a}}, 0\right)
\end{aligned}
$$

\section{References}

Ajayi, O. \& Dewar, A.M., 1982. The effect of barley yellow dwarf virus on honeydew production by the cereal aphids Sitobion avenae and Metopolophium dirhodum. Annals of Applied Biolology 100: 203-212.

Anderson, J.R., 1974. Simulation: methodology and application in agricultural economics. Review of Marketing and Agricultural Economics 70: 3-55.

Berge, H.F.M. ten, 1990. Heat and water transfer in the bare topsoil and the lower atmosphere. Pudoc, Wageningen. 207pp.

Boote, K.J., Jones, J.W., Mishoe, J.W. \& Berger, R.D., 1983. Coupling pests to crop growth simulators to predict yield reductions. Phytopathology 73: 1581-1587.

Carter, N. \& Rabbinge, R., 1980. Simulation models of the population development of Sitobion avenae. IOBC/WPRS Bulletin III/4: 93-98.

Coster, G., 1983. I. De zuigsnelheid van Sitobion avenae op tarwe. Internal Report, Department Theoretical Production Ecology. 33pp.

Daamen, R.A. \& Jorritsma, I.T.M., 1990a. Effects of powdery mildew and weather on winter wheat yield. 1. Variation of weather between years. Netherlands Journal of Plant Pathology 96: 29-34.

Neth. J. Pl. Path. 97 (1991) 
Daamen, R.A. \& Jorritsma, I.T.M., 1990b. Effects of powdery mildew and weather on winter wheat yield. 2. Effects of mildew epidemics. Netherlands Journal of Plant Pathology 96: $35-46$.

Dedryver, C.A., 1978. Biologie de pucerons des cereales dans l'Ouest de la France. I - Repartition et evolution des populations de Sitobion avenae F., Metopolophium dirhodum Wlk. et Rhopalosiphum padi L. de 1974 a 1977 sur ble d'hiver dans le bassin de Rennes. Annales de Zoologie Ecologie Animale 10: 483-505.

Dixon, A.F.G., 1975. Aphids and translocation. In: Zimmerman, M.H. \& Milburn, J.A. (Eds), Transport in plants. I. Phloem transport. Encyclopedia of Plant Physiology, New Series, Vol. 1. p. 153-170.

Entwistle, J.C. \& Dixon, A.F.G., 1987. Short-term forecasting of wheat yield loss caused by the grain aphid (Sitobion avenae) in summer. Annals of Applied Biolology 111: 489-508.

George, K.S., 1974. Damage assessment aspects of cereal aphid attack in autumn and springsown cereals. Annals of Applied Biolology 77: 67-74.

Goudriaan, J., 1988. The barebones of leaf angle distribution in radiation models for canopy photosynthesis and energy exchange. Agricultural and Forest Meteorology, 43: 155-169.

Groot, J.J.R., 1987. Simulation of nitrogen balance in a system of winter wheat and soil. Simulation Report CABO-TT nr. 13.69pp.

Hahn, G.J. \& Shapiro, S.S., 1967. Statistical models in engineering. John Wiley, New York.

Hertel, R. \& Kunkel, H., 1976. Wechselnde Verwertung chemisch definierter Nahrung durch Myzus persicae-Larven (Hempitera, Aphididae). Zoologische Jahrbücher, Abteilung für Allgemeine Zoologie und Physiologie der Tiere 80: 259-266.

IBM, 1975. Continuous System Modelling Program III (CSMP III), Program Reference Manual SH19-7001-2. IBM Corporation, White Plains, N.Y.

Jensen, S.G., 1969. Composition and metabolism of barley leaves infected with barley yellow dwarf virus. Phytopathology 59: 1694-1699.

Kenmore, P., 1980. Ecology and pest outbreaks of a tropical insect pest of the Green Revolution: The rice brown planthopper Nilaparvata lugens (Stal). Ph.D. dissertation, Division of Biological Pest Control, University of California, Berkeley. 226 pp.

Keulen, H. van \& Seligman, N.G., 1987. Simulation of water use, nitrogen nutrition and growth of a spring wheat crop. Pudoc, Wageningen. $310 \mathrm{pp}$

Kolbe, W., 1969. Untersuchungen ueber das Auftreten verschiedener Blattlausarten als Ursache von Ertrags- und Qualitaetsminderungen im Getreidebau. Pflanzenschutz-Nachrichten Bayer 26: 418-432.

Kropff, M., 1989. Quantification of $\mathrm{SO}_{2}$ effects on physiological processes, plant growth and crop production. Ph.D. thesis, Wageningen Agricultural University. 201 pp.

Latteur, G., 1976. Les pucerons des cereales: biologie, nuisance, ennemis. Centre de Recherches Agronomiques de l'Etat, Gembloux (la Belgique). Memoire no. 3.

Lee, G., Wratten, S.D. \& Kenyi, K.B.L., 1981. The effects of growth stage in cereals on yield reductions caused by aphids. Proceedings 1981 British Crop Protection Conference - Pests and Diseases. p. 449-456.

Llewellyn, M., 1988. Aphid energy budgets. In: Minks, A.K. \& Harrewijn, P. (Eds). Aphids, their biology, natural enemies and control. Volume 2B. Elsevier Science Publishers, Amsterdam. p. 109-117.

Mantel, W.P., Rabbinge, R. \& Sinke, J., 1982. Effekten van bladluizen op de opbrengst van wintertarwe. Gewasbescherming 13: 115-124.

Mittler, T.E., 1958. Studies on the feeding and nutrition of Tuberolachnus salignus (Gmelin) (Homoptera, Aphididae). II. The nitrogen and sugar composition of ingested phloem sap and excreted honeydew. Journal of Experimental Biology 35: 74-84.

Rabbinge, R., 1985. The bridge function of crop ecology. Netherlands Journal of Agricultural Science 3: 239-251. 
Rabbinge, R. \& Coster, G., 1984. Some effects of cereal aphids on growth and yield of winter wheat. In: Barley, P. \& Swinger, D. (Eds), Proceedings of the Fourth Australian Applied Entomological Research. 24-28 Sept. 1984. p. 163-169.

Rabbinge, R., Drees, E.M., van der Graaf, M., Verberne, F.C.M. \& Wesselo, A., 1981. Damage effects of cereal aphids in wheat. Netherlands Journal of Plant Pathology 87: 217-232.

Rabbinge, R. \& Mantel, W.P., 1981. Monitoring for cereal aphids in winter wheat. Netherlands Journal of Plant Pathology 87: 25-29.

Rabbinge, R. \& Rijsdijk, F.H., 1981. Disease and crop physiology: a modeller's point of view. In: Ayres, P.G., (Ed.), Effects of disease on the physiology of the growing plant. Cambridge University Press, Cambridge. p. 201-220.

Rabbinge, R., Sinke, C. \& Mantel, W.P., 1983. Yield loss due to cereal aphids and powdery mildew in winter wheat. Mededelingen van de Faculteit Landbouwwetenschappen Rijksuniversiteit Gent 48: 1159-1168.

Rabbinge, R. \& Vereijken, P.H., 1980. The effect of diseases or pests upon the host. Zeitschrift fuer Pflanzenkrankheiten und Pflanzenschutz 87: 409-422.

Rabbinge, R., Ward, S.A. \& Laar, H.H. van, (Eds), 1989. Simulation and systems management in crop protection. Pudoc, Wageningen. $420 \mathrm{pp}$.

Reitzel, J. \& Jakobsen, J., 1980. The occurrence of and damage caused by aphids in cereal crops in Denmark. Bulletin SROP / WPRS Bulletin 1980/III/4: 107-118.

Roermund, H.J.W. van, Groot, J.J.R, Rossing, W.A.H. \& Rabbinge, R., 1986a. Calculation of aphid damage in winter wheat, using a simulation model. Mededelingen van de Faculteit Landbouwwetenschappen Rijksuniversiteit Gent 51: 1125-1130.

Roermund, H.J.W. van, Groot, J.J.R, Rossing, W.A.H. \& Rabbinge, R., 1986b. Simulation of aphid damage in winter wheat. Netherlands Journal of Agricultural Science 34: 488-493.

Rossing, W.A.H., 1991. Simulation of damage in winter wheat caused by the grain aphid Sitobion avenae. 3. Calculation of damage at various attainable yield levels. Netherlands Journal of Plant Pathology 97, in press.

Rossing, W.A.H. \& Wiel, L.A.J.M. van de, 1990. Simulation of damage in winter wheat caused by the grain aphid Sitobion avenae. 1. Quantification of the effects of honeydew on gas exchange of leaves and aphid populations of different size on crop growth. Netherlands Journal of Plant Pathology 96: 343-364

Smedegaard-Petersen, V.\& Tolstrup, K., 1985. The limiting effect of disease resistance on yield. Annual Review of Phytopathology 23: 475-490.

Smedegaard-Petersen, V., 1982. The effect of defence reactions on the energy balance and yield of resistant plants. In: Wood, R.K.S. (Ed.), Active defence mechanisms in plants. Plenum, New York. p. 299-315.

Spiller, N.J. \& Llewellyn, M., 1987. Honeydew production and sap ingestion by the cereal aphids Rhopalosiphum padi and Metopolophium dirhodum on seedlings of resistant and susceptible wheat species. Annals of Applied Biology 110: 585-590.

Spitters, C.J.T., 1986. Separating the diffuse and direct component of global radiation and its implications for modelling canopy photosynthesis. II. Calculations of canopy photosynthesis. Agricultural and Forest Meteorology, 38: 231-242.

Spitters, C.J.T., 1989. Weeds: Population dynamics, germination and competition. In: Rabbinge, R., Ward, S.A. \& Laar, H.H. van (Eds), 1989. Simulation and systems management in crop protection. Pudoc, Wageningen. p. 182-216.

Teng, P.S., Blackie, M.J. \& Close, R.C., 1980. Simulation of the barley leaf rust epidemic: structure and validation of BARSIM-I. Agricultural Systems 5: 85-103.

Vereijken, P.H., 1979. Feeding and multiplication of three aphid species and their effect on yield of winter wheat. Agricultural Research Reports 888. Pudoc, Wageningen. 58 pp.

Watt, A.D., Vickerman, G.P. \& Wratten, S.D., 1984. The effect of the grain aphid, Sitobion avenae (F.), on winter wheat in England: an analysis of the economics of control practice and

Neth. J. Pl. Path. 97 (1991) 
forecasting systems. Crop Protection 3: 209-222.

Wellings, P.W., Ward, S.A., Dixon, A.F.G. \& Rabbinge, R., 1989. Crop loss assessment. In: Minks, A.K. \& Harrewijn, P. (Eds), Aphids, their biology, natural enemies and control. Volume 2C. Elsevier Science Publishers, Amsterdam. p. 49-64.

Wetzel, T., Freier, B. \& Heyer, W., 1980. Zur Modellierung von Befall-Schadensrelationen wichtiger Schadinsekten des Winterweizen. Zeitschrift für Angewandte Entomologie 89: 330-334. Wratten, S.D., 1978. Effects of feeding position of the aphids Sitobion avenae and Metopolophium dirhodum on wheat yield and quality. Annals of Applied Biology 90: 11-20.

Zadoks, J.C., Chang, T.T. \& Konzak, C.F., 1974. A decimal code for the growth stages of cereals. Eucarpia Bulletin 7: 42-52. 